$1 / 2 / 2^{8}-9045(1)$

\title{
Radiological Standards and Calibration Laboratory Capabilities
}

R. W. Goles

January 1995

Prepared for the U.S. Department of Energy under Contract DE-AC06-76RLO 1830

Pacific Northwest Laboratory

Operated for the U.S. Department of Energy

by Battelle Memorial Institute 


\title{
DISCLAIMER
}

This report was prepared as an account of work sponsored by an agency of the United States Government. Neither the United States Government nor any agency thereof, nor Battelle Memorial institute, nor any of their employees, makes any warranty, expressed or implied, or assumes any legal liability or responsibility for the accuracy, completeness, or usefulness of any information, apparatus, product, or process disclosed, or represents that its use would not infringe privately owned rights. Reference herein to any specific commercial product, process, or service by trade name, trademark, manufacturer, or otherwise does not necessarily constitute or imply its endorsement, recommendation, or favoring by the United States Government or any agency thereof, or Battelle Memorial Institute. The views and opinions of authors expressed herein do not necessarily state or reflect those of the United States Government or any agency thereof.

\author{
PACIFIC NORTHWEST LABORATORY \\ operated by \\ BATTELLE MEMORIAL INSTITUTE \\ for the \\ UNITED STATES DEPARTMENT OF ENERGY \\ under Contract DE-AC06-76RLO 1830
}

Printed in the United States of America

Available to DOE and DOE contractors from the

Office of Scientific and Technical Information, P.O. Box 62, Oak Ridge, TN 37831; prices available from (615) 576-8401. FTS 626-8401.

Available to the public from the National Technical Information Service, U.S. Department of Commerce, 5285 Port Royal Rd., Springfield, VA 22161. 


\section{DISCLAIMER}

Portions of this document may be illegible in electronic image products. Images are produced from the best available original document. 
PNL-10354

UC-607

Radiological Standards and Calibration Laboratory Capabilities

R. W. Goles

Technical Contributors:

R. K. Piper

J. D. Peters

D. R. Sisk

January 1995

Prepared for

the U.S. Department of Energy

under Contract DE-AC06-76RLO 1830

Pacific Northwest Laboratory

Richland, Washington 99352

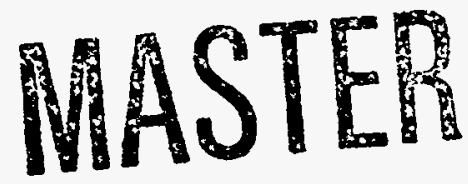




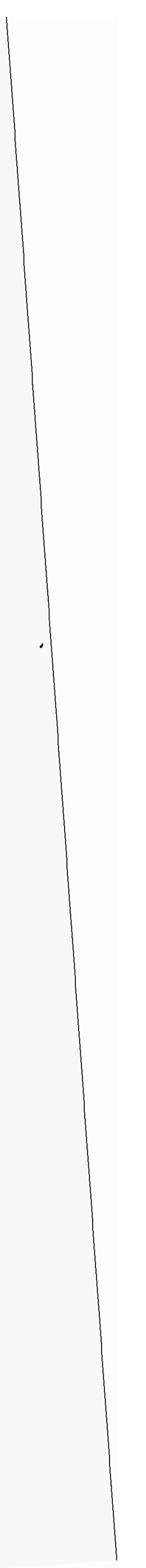




\section{Summary}

The Radiological Standards and Calibration Laboratory at Pacific Northwest Laboratory (PNL) performs instrument and dosimetry calibrations, maintains reference standards necessary to trace the Hanford Site programs and other research programs to national radiological standards, and conducts performance evaluations to qualify the health physics instrumentation used on the Hanford Site. The facilities and procedures used to accomplish this mission are described in this technical report. The work routinely includes calibrations of personnel dosimeters, health physics instrumentation, and radioactive photon-, neutron-, beta- and alpha-particle sources.

The specialized facilities developed to support radiological calibrations, dosimetry, and instrument performance evaluations include:

- a low-scatter room that provides neutron $\left(\mathrm{D}_{2} \mathrm{O}\right.$-moderated and unmoderated $\left.{ }^{252} \mathrm{Cf}\right)$ and gamma $\left({ }^{60} \mathrm{Co}\right.$ and $\left.{ }^{137} \mathrm{Cs}\right)$ irradiations in a free-space geometry

- a source well room equipped with four calibration source wells ( 3 gamma and 1 neutron) designed to expedite routine instrument calibrations

- an X-ray laboratory that produces bremsstahlung and K-fluorescent (NIST technique) beam spectra and an open $(2 \pi)^{241} \mathrm{Am}$ irradiation source

- a high-exposure facility capable of delivering a large volume, uniform gamma radiation field $\left(0.08 \mathrm{R} / \mathrm{h}\right.$ to $\left.\sim 2 \times 10^{4} \mathrm{R} / \mathrm{h}\right)$ for standard calibrations or testing of radiation measuring instrumentation

- a beta-particle laboratory that maintains ${ }^{204} \mathrm{Tl},{ }^{147} \mathrm{Pm}$, and ${ }^{90} \mathrm{Sr} /{ }^{90} \mathrm{Y}$ as international secondary standard sources for dosimetry characterization

- instrument calibration and evaluation laboratories that provide the flexibility required to calibrate a wide range of portable and semiportable radiological instrumentation and radioactive sources and to diagnose and overcome operational problems encountered by instrument users

- instrument testing rooms that allow the operation of health physics instruments to be evaluated against American National Standards Institute (ANSI) performance standards (e.g., ANSI N42.17A and ANSI N42.17C)

- the U.S. Department of Energy (DOE) accredited thermoluminescent dosimetry laboratories that directly support the Hanford Site personnel, environmental, and nuclear accident dosimetry programs

- high-intensity irradiators, including a high-level ${ }^{60} \mathrm{Co}$ irradiator and a tandem Van de Graaff accelerator, that support specialized or high-dose studies. 
Pacific Northwest Laboratory, in support of the Hanford Site's Radiological Standards and Calibration Laboratory, has been accredited as a Secondary Calibration Laboratory for Ionizing Radiation (SCLIR) through the National Voluntary Laboratory Accreditation Program (NVLAP). This accreditation implies the concurrence by the National Institute of Standards and Technology (NIST) that PNL provides highly accurate instrument calibrations and dosimeter irradiations and that the laboratory complies with NIST Special Publication 812 (U.S. Department of Commerce/National Institute of Standards and Technology 1991). Similarly, PNL's External Dosimetry Program has also been accredited by DOE since the inception of DOE's Laboratory Accreditation Program (DOELAP) in 1989. 


\section{Contents}

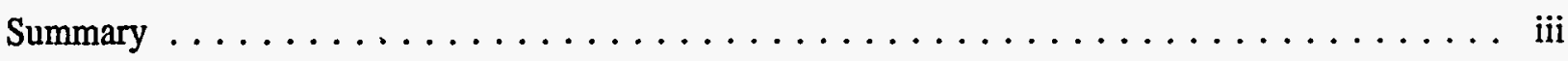

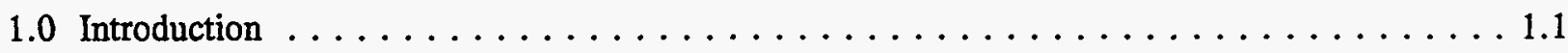

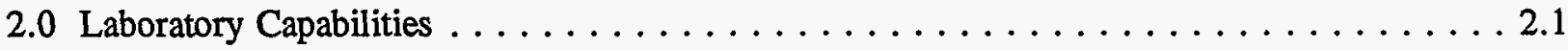

2.1 Calibration Laboratory Layout $\ldots \ldots \ldots \ldots \ldots \ldots \ldots \ldots \ldots \ldots \ldots \ldots \ldots \ldots$

2.2 Facilities Descriptions $\ldots \ldots \ldots \ldots \ldots \ldots \ldots \ldots \ldots \ldots \ldots \ldots \ldots \ldots \ldots \ldots \ldots \ldots \ldots \ldots .2$

2.2.1 Low-Scatter Room (Room 106) $\ldots \ldots \ldots \ldots \ldots \ldots \ldots \ldots \ldots \ldots \ldots \ldots \ldots$

2.2.2 Source Well Room (Room 121) $\ldots \ldots \ldots \ldots \ldots \ldots \ldots \ldots \ldots \ldots \ldots .2$

2.2.3 X-Ray Facilities and Capabilities (Room 6) $\ldots \ldots \ldots \ldots \ldots \ldots \ldots .2$

2.2.4 High-Exposure Facility (Room 8) $\ldots \ldots \ldots \ldots \ldots \ldots \ldots \ldots \ldots \ldots \ldots$

2.2.5 BETA Standards Laboratory (Room 113) $\ldots \ldots \ldots \ldots \ldots \ldots \ldots \ldots . .5$

2.2.6 Instrument Calibration and Evaluation Laboratories $\ldots \ldots \ldots \ldots \ldots \ldots 2.6$

2.2.7 ANSI Testing Laboratory (Rooms 127 and 131) $\ldots \ldots \ldots \ldots \ldots \ldots 2.6$

2.2.8 Instrument Repair Shop (Trailer) $\ldots \ldots \ldots \ldots \ldots \ldots \ldots \ldots \ldots \ldots$

2.2.9 Thermoluminescence Dosimetry Laboratory (Rooms 147,148 and 163) . . . . 2.6

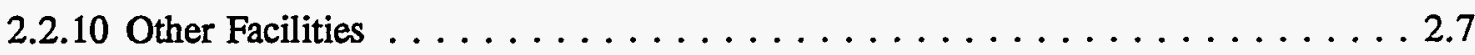

3.0 Laboratory Standards and Traceability Program $\ldots \ldots \ldots \ldots \ldots \ldots \ldots \ldots .1$

3.1 Quality Assurance Program $\ldots \ldots \ldots \ldots \ldots \ldots \ldots \ldots \ldots \ldots \ldots \ldots \ldots \ldots \ldots \ldots \ldots$

3.2 Local Standards and Traceability Program $\ldots \ldots \ldots \ldots \ldots \ldots \ldots \ldots .2$

3.3 Computer and Data Management Facilities $\ldots \ldots \ldots \ldots \ldots \ldots \ldots \ldots \ldots .2$

Appendix - Photographs of the Radiological Standards and Calibrations Laboratory . . . . . A A.1 


\subsection{Introduction}

The Radiological Standards and Calibrations Laboratory, a part of Pacific Northwest Laboratory (PNL), ${ }^{(a)}$ performs calibrations and upholds reference standards necessary to maintain traceability to national radiological standards. The facility supports U.S. Department of Energy (DOE) programs at the Hanford Site, programs sponsored by DOE Headquarters and other federal agencies, radiological protection programs at other DOE sites, and research programs sponsored through the commercial sector.

The laboratory is located in the 318 Building of the Hanford Site's 300 Area. The facility contains five major exposure rooms and several laboratories used for exposure work preparation, low-activity instrument calibrations, instrument performance evaluations, instrument maintenance, instrument design and fabrication work, and thermoluminescent and radiochromic dosimetry. The major exposure facilities are a low-scatter room used for neutron and photon exposures, a source well room used for high-volume instrument calibration work, an x-ray facility used for energy response studies, a highexposure facility used for high-rate photon calibration work, and a beta standards laboratory used for beta energy response studies and beta reference calibrations. Calibrations are routinely performed for personnel dosimeters, health physics instrumentations, photon transfer standards and alpha, beta and gamma field sources used throughout the Hanford Site.

This report describes the standards and calibrations laboratory. Photographs that accompany the text appear in the Appendix and are designated Figure A.1 through A.29.

(a) Pacific Northwest Laboratory is operated for the U.S. Department of Energy by Battelle Memorial Institute under Contract DE-AC06-76RLO 1830. 


\subsection{Laboratory Capabilities}

\subsection{Calibration Laboratory Layout (Figures A.1 and A.2)}

The laboratory is located in the basement and first floor of the multistory section of the 318 Building, the south wing of the 318 Building, and the adjoining trailer complex. A covered hallway connects the trailer complex with the south wing to allow for moving instruments to and from the Trailer 4 maintenance shop.

The 318 Building facility, originally a test reactor facility, was converted to the Radiological Standards and Calibration Laboratory in 1984. The upper containment room (Room 106), having concrete surfaces with an inner dimension of $10 \mathrm{~m} \times 17 \mathrm{~m} \times 9 \mathrm{~m}$ high, $(33 \mathrm{ft} \times 55 \mathrm{ft} \times 30 \mathrm{ft}$ ) was converted into a low-scatter facility. The lower containment area was partitioned into a high-exposure rate facility and an $x$-ray facility. The basement also contains a source storage room and two thermal neutron sources: a graphite moderated pile and a heavy-water moderation tank.

On the ground floor outside the low-scatter facility is the dosimeter make-up room used to prepare exposure sets for the low-scatter room work, the beta standards laboratory, and the nuclear criticality detector calibration laboratory.

The south wing, which was constructed and expanded twice to accommodate increased demands for Site calibration and dosimetry services, contains the source well room; instrument and sealed source evaluation, calibration, and testing laboratories; dosimeter preparation and analysis laboratories; and instrument and dosimeter receiving rooms. An instrument repair shop as well as a dosimetry development laboratory, both located in a trailer that is permanently connected to the building's south wing, support the calibration and dosimetry programs. A third facility expansion, scheduled to begin at the end of 1994, will provide for additional office space.

Instruments and/or sealed sources used on the Hanford Site are routinely delivered to the laboratory's receiving room where they are logged in and checked for contamination. Following check-in, instruments are either routed to the repair shop or to either the source well room or appropriate calibration laboratory, depending on the state of the instrument and its purpose. Sealed radiation sources are routed directly to the Source Laboratory, which provides low-level alpha-, beta-, and gamma-source calibration services.

The instrument evaluation laboratory is used to evaluate the performance of new instrumentation arriving at the Hanford Site and to develop and test instrumentation for specialized purposes. The testing laboratory, on the other hand, provides the capability of performance testing health physics instruments to all applicable American National Standards Institute (ANSI) operational standards.

The dosimetry laboratories are used to provide external dose-of-record information for Hanford personnel as required by DOE in the Hanford Site Radiological Control Manual (RL 1992), DOE 5480.11 (1988a), and DOE 5480.15 (1987). In addition, these laboratories support Hanford and off-site sponsored dosimeter development programs and environmental field measurement capabilities. 


\subsection{Facilities Descriptions}

\subsubsection{Low-Scatter Room (Room 106) (Figures A.3 through A.6)}

The low-scatter room is a large irradiation area with an extremely low albedo for the neutron calibration station housed within. The room has concrete walls and is approximately $10 \mathrm{~m} \mathrm{x} 9 \mathrm{~m} \mathrm{x} 15 \mathrm{~m}$ $(33 \mathrm{ft} \times 30 \mathrm{ft} \times 49 \mathrm{ft}$ ) in size. The neutron source irradiation station is mounted on a raised aluminum platform located approximately at the geometrical center of the room. Another irradiation station is also located at floor level. A pneumatically driven "rabbit" system is used to move sources from their storage locations to any of the irradiation stations. A control console allows the operator to select the source and position along with the irradiation duration. The control system indicates the position of the source (either in storage or at a station) and will also automatically return the source to storage and safely shut down the system in case of a malfunction.

The functional capabilities of each of the irradiation stations within the low-scatter room are described below.

- The elevated neutron station is used for $\mathrm{D}_{2} \mathrm{O}$-moderated ${ }^{252} \mathrm{Cf}$ irradiations as specified by ANSI Standard N13.11 and the DOE dosimetry testing standard. Bare ${ }^{252} \mathrm{Cf}$ irradiations specified by the DOE standard are also carried out at this station by removing the $\mathrm{D}_{2} \mathrm{O}$ moderator sphere.

- The floor-level station is used for bare ${ }^{252} \mathrm{Cf},{ }^{60} \mathrm{Co}$, and ${ }^{137} \mathrm{Cs}$ irradiations. The station has a ring shaped table constructed of low-density foam to minimize scatter. This table supports pencil or TLD dosimeters at distances of 50 and $100 \mathrm{~cm}$ from the source. The ring design enables the simultaneous irradiation of many dosimeters to a single source.

\subsubsection{Source Well Room (Room 121) (Figures A.7 and A.8)}

Four calibration source wells are located in Room 121 of the calibration facility. Each well is $0.3 \mathrm{~m}(0.98 \mathrm{ft})$ in diameter by $10 \mathrm{~m}(33 \mathrm{ft})$ deep and contains a trolley-mounted, double-encapsulated radionuclide source. Trolley movement is controlled by a dedicated personal computer programmed to position the source to provide the desired exposure or dose equivalent rate at the top of the well. Source-to-detector distances are automatically corrected to compensate for temperature, pressure, and source decay. Wells 1 and 2 contain $0.4 \mathrm{Ci}$ and $8 \mathrm{Ci}$ of ${ }^{137} \mathrm{Cs}$, respectively, and provide $662 \mathrm{keV}$ photon fields from $2 \mathrm{mr} / \mathrm{h}$ up to approximately $10 \mathrm{R} / \mathrm{h}$. The available ${ }^{137} \mathrm{Cs}$ dose rates provided by this well facility will soon be increased $(\sim 2 \mathrm{x})$ when the existing $8-\mathrm{Ci}$ source is replaced by a newly procured 20-Ci source. Well 3 contains $29 \mathrm{mCi}(10 / 94)$ of ${ }^{252} \mathrm{Cf}$, which provides neutron dose equivalent rates from $2 \mathrm{mrem} / \mathrm{h}$ up to $400 \mathrm{mrem} / \mathrm{h}$ for standard Site neutron monitors (SNOOPY). Well 4 contains $0.2 \mathrm{Ci}$ of ${ }^{60} \mathrm{Co}$, which provides $1.25 \mathrm{MeV}$ (avg.) photon fields from $6 \mathrm{mr} / \mathrm{h}$ up to $2 \mathrm{R} / \mathrm{h}$. Together, the calibration wells make it possible to perform instrument calibrations and evaluations over a wide range of exposure rates with minimum radiation exposure to the operator.

\subsubsection{X-Ray Facilities and Capabilities (Room 6) (Figures A.9 through A.13)}

The x-ray laboratory consists of a shielded control room and a $4.7 \mathrm{~m} \mathrm{x} 12.6 \mathrm{~m} \mathrm{x} 4 \mathrm{~m}$ (15-ft x 41-ft x 13-ft) irradiation room. Two identical Philips Model-324 x-ray machines are currently in use to support of PNL instrument calibration/personnel dosimetry activities. One machine produces 
bremsstrahlung (broad) photon spectra (e.g., NIST techniques M30, S60, M150, H150, etc.), while the second is configured to facilitate production of $\mathrm{K}$-fluorescence technique (narrow) secondary photon spectra (e.g., K17 and K59) within a shielded enclosure. Table 2.1 is a complete list of available techniques and their characteristics. Both of these $x$-ray generating systems use a laser alignment system to aid in device (instrument/dosimeter) positioning.

Traceability of calibrations to the NIST is maintained through intercomparison standards. An ongoing measurement quality assurance interaction (proficiency testing) with NIST further strengthens the NIST/PNL link.

The PNL $x$-ray facilities offer quality controlled irradiation applications for both photon detector response characterization and personnel dosimetry systems following current DOE and ANSI standards.

Table 2.1. Available X-Ray Photon Techniques ${ }^{(a)}$

\begin{tabular}{|c|c|c|c|c|c|}
\hline Style & Technique & $\begin{array}{c}\text { Average/ } \\
\text { Effective } \\
\text { Energy (keV) } \\
\end{array}$ & $\begin{array}{c}\text { Half-Value } \\
\text { Layer } \\
\text { (mm Al) }\end{array}$ & $\begin{array}{c}\text { Homogeneity } \\
\text { Coefficient }\end{array}$ & $\begin{array}{c}\text { Exposure } \\
\text { Rate/Range } \\
(\mathrm{R} / \mathrm{h})^{(\mathrm{b})}\end{array}$ \\
\hline \multirow[t]{14}{*}{ Bremsstrahlung } & M20 & 12.8 & 0.150 & 0.790 & $2.9-288.6$ \\
\hline & 1130. & $20 \%$ & 0354 & 6634 & $3.2 \times 3 \% 6$ \\
\hline & 1,456 & 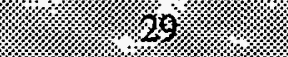 & $10996 \%$ & $0.650 \%$ & 3.4 .350 .9 \\
\hline & 14 ago & 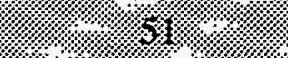 & $1=1.86 \%$ & 62120 & $.5+3650$ \\
\hline & 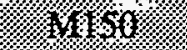 & 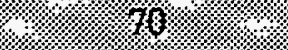 & $9.9 \%$ & 0.862. & $38.39 \% 14$ \\
\hline & $\mathrm{M} 200$ & 84 & $\mathrm{~N} / \mathrm{A}$ & $\mathrm{N} / \mathrm{A}$ & $4.3-431.0^{\circ}$ \\
\hline & 960 & 6 & $2 / 2$ & $0 \% 61$ & 06.196 \\
\hline & 3\% & 30 & $4 x$ & $4: 6$ & $4.6-4.92 .2$ \\
\hline & H50 & 38 & N/A & N/A & $0.05-9.40$ \\
\hline & H100 & 70 & 13.47 & 0.964 & $0.02-3.07$ \\
\hline & 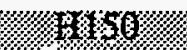 & 129 & K6y & $0 \% 80$ & $0 \% 2=165$ \\
\hline & $\mathrm{H} 200$ & 167 & 20.22 & 0.994 & $0.09-9.22$ \\
\hline & $\mathrm{H} 250$ & 210 & 22.48 & 0.987 & $0.09-8.50$ \\
\hline & H300 & 252 & 23.87 & 0.898 & $0.06-5.63$ \\
\hline \multirow[t]{7}{*}{ K-Fluorescence } & K8.6 & 8.6 & $\mathrm{~N} / \mathrm{A}$ & N/A & 20.43 \\
\hline & $\mathrm{K} 17.0$ & 17.5 & $\mathrm{~N} / \mathrm{A}$ & N/A & 3.64 \\
\hline & K25.3 & 25.3 & N/A & N/A & 3.74 \\
\hline & $\mathrm{K} 31.0$ & 31 & N/A & N/A & 1.55 \\
\hline & K40.1 & 40.1 & N/A & N/A & 1.51 \\
\hline & K49.1 & 49.1 & N/A & N/A & 0.86 \\
\hline & K59.0 & 59.3 & N/A & $\mathrm{N} / \mathrm{A}$ & 0.96 \\
\hline
\end{tabular}

(a) Routine calibration maintained only for shaded techniques.

(b) Nominal. 


\subsubsection{High-Exposure Facility (Room 8) (Figures A.14 through A.17)}

The high-exposure facility is capable of delivering a large volume uniform gamma radiation field of $0.08 \mathrm{R} / \mathrm{h}$ to $>2 \times 10^{4} \mathrm{R} / \mathrm{h}$ for standard calibration or testing of radiation measuring instruments. Table 2.2 lists the radiation sources and exposure capabilities of the facility as it presently exist. However, facility ${ }^{60} \mathrm{Co}$ dose rates will soon be significantly increased when a newly procured $6,000-\mathrm{Ci}$ source is loaded into carousel position 4.

The high-exposure facility has two ${ }^{137} \mathrm{Cs}$ and two ${ }^{60} \mathrm{Co}$ encapsulated sources that are pneumatically raised into exposure position from a shielded storage location. In the exposure position, the source capsule is shielded by a 2-1/2-ton lead shielded exposure column that establishes the exposure (beam) geometry. A $30^{\circ}$, conical opening $\left(15^{\circ}\right.$ cone angle) presents a horizontal radiation field for instrument

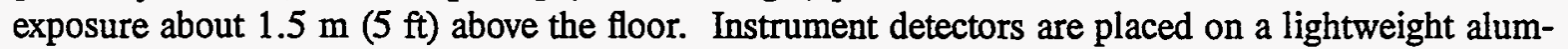
inum trolley cart on rails in front of the cone opening. The trolley cart is moved by a stepping motor along a cog rail. The precise location is transmitted from the linear displacement transducer to the remote console readout. The 6-m (19-ft) -long rails provide a 140:1 ratio in available exposure rates for each source.

Once the detector has been positioned on the trolley cart and connected to a remote readout, all operations may be conducted at the remote operating console located outside the concrete shielded exposure room. Cabling runs from the trolley cart to the remote console for most radiation instruments. For instruments that cannot be operated remotely, a TV camera is used to monitor instrument responses at the operator console.

The dimensions of the exposure room are $15.2 \mathrm{~m} \mathrm{x} 3.7 \mathrm{~m} \mathrm{x} 3.7 \mathrm{~m}(50 \mathrm{ft} \times 12 \mathrm{ft} \times 12 \mathrm{ft})$. The

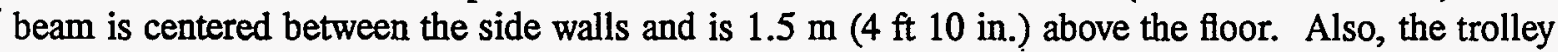
cart rails end $1.8 \mathrm{~m}(6 \mathrm{ft})$ away from the back wall. In this way, the solid surfaces are far enough away that any reflected radiation is insignificant compared to the main beam.

Table 2.2. High-Exposure Facility Radiation Sources and Exposure Range Capabilities

\begin{tabular}{|c|c|c|}
\hline $\begin{array}{l}\text { Carousel } \\
\text { Position }\end{array}$ & $\begin{array}{c}\text { Radiation } \\
\text { Source }(9 / 1 / 94)\end{array}$ & $\begin{array}{l}\text { Available Exposure } \\
\text { Rates }^{(\mathrm{a})}(\mathrm{R} / \mathrm{h})\end{array}$ \\
\hline Safe & 0 & 0 to 0 \\
\hline 1 & $8 \mathrm{Ci}{ }^{137} \mathrm{Cs}$ & 0.1 to 30 \\
\hline 2 & $80 \mathrm{Ci}^{137} \mathrm{Cs}$ & 1 to 300 \\
\hline 3 & $165 \mathrm{Ci}^{60} \mathrm{Co}$ & 5.7 to 1,850 \\
\hline $4^{(b)}$ & $1,470 \mathrm{Ci}^{60} \mathrm{Co}$ & 51 to 17,000 \\
\hline
\end{tabular}

(a) The highest exposure rate is a distance of about $50 \mathrm{~cm}$ (19 in.). Exposure rates four times this value within a very limited field can be achieved at distances $<25 \mathrm{~cm}$ (10 in.).

(b) To be upgraded to $6,000 \mathrm{Ci}$ during the first quarter of calendar year 1995 . 
The four sources are in a five-position, 41-cm (16-in.) -diameter carousel located below floor level. From this carousel, the capsules are raised to exposure position like a rotameter float by the air circulation pump that blows air up from under the carousel, and sucks it out the top of the exposure column.

From the remote control console, the sources can be rotated into alignment with the exposure column and raised to exposure position. Also, the trolley cart can be positioned and repositioned to any location along the length of the track. Exposure rates ranging from $80 \mathrm{mR} / \mathrm{h}$ to over $17,000 \mathrm{R} / \mathrm{h}$ can be remotely controlled from the console.

Extensive precautions are in place to prevent personnel exposure during facility operations. An Area Radiation Monitor always turns on a flashing red light whenever a source is in the exposure position. If the light's filament is burned out, the source cannot be raised. To initiate carousel operation, the search button in the facility room must be pressed to set off a 20-s alarm. Within this time period, the room door must be shut, and the console "on" button must be pressed. Three abort buttons located in the facility room may be pressed to stop the source mechanism and return the carousel to the safe position.

\subsubsection{BETA Standards Laboratory (Room 113) (Figure A.16)}

Room 113 of the 318 Building contains a beta calibration apparatus (manufactured by Buchler GmbH \& Co.). The apparatus consists of a source jig mounted on an optical bench, an operator console, and various beta sources. Dosimeters, mounted on phantoms, and instruments are irradiated within a beam geometry; beam uniformity is enhanced by beam flattening filters.

These four sources are included with the original Physikalisch-Techische Bundesanstalt (PTB): 1) a $50-\mathrm{mCi}(1,850 \mathrm{MBq}){ }^{90} \mathrm{Sr} /{ }^{90} \mathrm{Y}$ source, 2) a $2-\mathrm{mCi}(74 \mathrm{MBq}){ }^{90} \mathrm{Sr} /{ }^{90} \mathrm{Y}$ source, 3) a $0.5-\mathrm{mCi}$ $(18.5 \mathrm{MBq}){ }^{204} \mathrm{Tl}$ source, and 4) a $14-\mathrm{mCi}(518 \mathrm{MBq}){ }^{147} \mathrm{Pm}$ source.

These sources have been constructed by Amersham in accordance with the International Standards Organization (ISO) 6980. The beta sources were calibrated at the PTB. Nominal dose rates at reference distances are as follows for new source sets:

$$
\begin{array}{lc}
{ }^{90} \mathrm{Sr} /{ }^{90} \mathrm{Y} & 25 \mathrm{rad} / \mathrm{h} \\
{ }^{90} \mathrm{Sr} / 90 \mathrm{Y} & 600 \mathrm{mrad} / \mathrm{h} \\
{ }^{204} \mathrm{Tl} & 50 \mathrm{mrad} / \mathrm{h} \\
{ }^{147} \mathrm{Pm} & 30 \mathrm{mrad} / \mathrm{h} .
\end{array}
$$

The sources and irradiation apparatus compose an international secondary standard for beta irradiations.

In addition to the above sources, several sources from U.S. manufacturers have been configured for use with this system. Two of these are ${ }^{90} \mathrm{Sr} /{ }^{90} \mathrm{Y}$ sources with modified encapsulation to meet specifications listed in ANSI N13.11. Another is a ${ }^{204} \mathrm{Tl}$ source of much higher activity than its PTB 
counterpart. Measurements have been made of all Amersham-Buchler sources and the Amersham-U.S. ${ }^{90} \mathrm{Sr} /{ }^{90} \mathrm{Y}$ sources to verify satisfactory compliance with ANSI N13.11 (1983), DOE/EH-0027 (1986), and ISO 6980 (1984).

\subsubsection{Instrument Calibration and Evaluation Laboratories}

The calibration facility has several multipurpose laboratories designed to provide the flexibility required to calibrate a wide range of portable and semiportable radiological instrumentation and radioactive sources. These laboratories include rooms 116, 122, 124, 126, and 129. The laboratories are fully equipped with a variety of electronic gear including nuclear pulse generators, digital voltmeters, multichannel analyzers, high-voltage power supplies, amplifiers, oscilloscopes, and scalers. A variety of small alpha-, beta- and gamma-emitting radionuclide sources are also available. Room 122 has an environmental chamber for environmental testing of radiological instruments, and Room 126 has a high-efficiency particulate air-filtered fume hood for work with solvents. The types of instruments calibrated in these laboratories include portable instruments as well as area radiation monitors, air monitors, personnel contamination monitors, and hand and shoe counters. Alpha, beta, and gamma instrument response check sources used to support plant operations are also calibrated in these laboratories using standards that are explicitly traceable to NIST.

\subsubsection{ANSI Testing Laboratory (Rooms 127 and 131) (Figures A.1 through A.23)}

In addition to routine calibration and evaluation capabilities, the Radiological Standards and Calibration Laboratory also possesses specialized testing capabilities that allow controlled, operational evaluations of health physics instrumentation to be performed against ANSI performance standards (e.g., ANSI N42.17A and ANSI N42.17C). This fully operational laboratory is designed to characterize the effects of temperature, pressure, humidity, vibration, acceleration, ac power, and microwave/ $\mathrm{RF} / \mathrm{E} \& \mathrm{M}$ fields on operational instrumental responses. These capabilities are routinely used to qualify new instruments on the Hanford Site.

\subsubsection{Instrument Repair Shop (Trailer) (Figure A.24)}

A complete instrument repair shop is located in the Trailer 4 addition of the calibration facility. The shop is capable of housing up to six instrument repair technicians along with the equipment required to repair and maintain portable and semiportable radiological instruments. Shop capabilities also include minor machining and instrument modification.

\subsubsection{Thermoluminescence Dosimetry Laboratory (Rooms 147, 148 and 163) (Figures A.25 to A.29)}

The External Dosimetry Program at PNL has also been accredited by DOE since the inception of DOE's Laboratory Accreditation Program (DOELAP) in 1989. Evaluation of thermoluminescent phosphors is routinely conducted to support the Hanford Site Personnel, Environmental, and Nuclear Accident Dosimetry Programs. Characterizations of radiation dose and depth profile are conducted for several different laboratory sources as well as for personnel work locations. The Laboratory satisfies multiple program needs for high-quality thermoluminescent dosimetry in a consistent manner. 
The Laboratory has several different thermoluminescent readers including the Harshaw 2000, 2080,8800 , and Atlas "hot gas" systems. All types of commercially available phosphors have been processed. Glow curves are routinely monitored to ensure accurate phosphor heating and peak integration. Phosphors are annealed in an atmospherically controlled oven for preset time and temperature conditions. Laboratory lighting and temperature are regulated to minimize potential external sources of contaminants to the radiation-induced signal in the different phosphors. Dose, energy, radiation type and environmental response characteristics have been determined for all commonly used commercial phosphors.

\subsubsection{Other Facilities}

\section{Gamma Beam 650 (331 Building)}

The Gamma Beam 650 is a ${ }^{60} \mathrm{Co}$ irradiation unit manufactured by Atomic Energy of Canada, Limited and used in the high-intensity irradiation room in the 331 Building. The facility can be used for high-exposure dosimetry including radiochromic dye dosimeters and high-level gamma monitors (ion chambers). The pneumatically operated irradiator facilitates high dose rate cavity and panoramic irradiations. The unit consists of a single lead-filled cylindrical source head with an upper assembly of 12 source exposure tubes set in a cylindrical configuration. Sample materials can be irradiated either centrally on a platform located at the center of the exposure tube assembly or panoramically by positioning the sample material in the air space around the unit. The total source strength of the combined ${ }^{60} \mathrm{Co}$ sources is roughly $20,000 \mathrm{Ci}(1994)$, and the reference dose rate at $12-1 / 2 \mathrm{in}$. (32 cm) above the top of the central table with all sources exposed is roughly $4 \mathrm{Mrad} / \mathrm{h}$.

\section{Acceleration Facilities (3746 Building)}

The accelerator facility at PNL serves a broad base of research activities including research in radiation dosimetry. To support the wide range of research interests, a versatile facility with many unique features has been developed along with a staff highly experienced in accelerator physics and radiation dosimetry.

Charged Particle Beams. The accelerator facility providés positive ions with energies from a few $\mathrm{keV}$ to several $\mathrm{MeV}$ and electron beams energies from 0.1 to $2 \mathrm{MeV}$. Ion beams can be produced by any one of four accelerators including a low-energy ion source ( 2 to $100 \mathrm{kV}$ ), a 0.5 -MV Van de Graaff ( 50 to $500 \mathrm{keV}$ ), a 2-MV Van De Graaff (300 to $2000 \mathrm{keV}$ ), and a 2-MV tandem accelerator ( 800 to $4200 \mathrm{keV}$ ). These energies are quoted for singly charged ions.

Neutrons. The 2-MV positive ion Van de Graaff accelerator is also fully instrumented to produce neutrons using one of several available nuclear reactions. By properly selecting beam/target combinations, monoenergetic neutrons can be produced at one of numerous energies from a few $\mathrm{keV}$ to $14 \mathrm{MeV}$. For higher flux of $14-\mathrm{MeV}$ neutrons (up to $10^{10}$ neutron/s), a Kaman Nuclear $\mathrm{T}(\mathrm{d}, \mathrm{n})$ neutron generator is also available. Accelerator-produced neutrons are generated in a low-scatter room to optimize spectral purity. State-of-the-art neutron counting equipment, including a precision long encounter, ${ }^{3} \mathrm{He}$ spectrometer, and time-of-flight spectrometer are available to experimenters. The neutron exposure facility has a wide variety of uses including characterization of personnel dosimeters and portable neutron dosimeters, neutron cross section measurements, and irradiation of biological samples. 
High-Dose Studies. The 2-MV electron Van de Graaff accelerator provides a unique tool for high-dose and dose-rate experiments using either direct electron or x-ray exposures. Dose rates of $2,000 \mathrm{R} / \mathrm{h}$ for $\mathrm{x}$-rays or $5 \times 10^{9} \mathrm{rad} / \mathrm{h}$ for direct beams of electrons are readily available for target areas of a few $\mathrm{cm}^{2}$ using beams. For short electron beam pulses, dose-rates approaching $10^{14} \mathrm{rad} / \mathrm{h}$ are possible. 


\subsection{Laboratory Standards and Traceability Program}

The Radiological Standards and Calibration Laboratory is charged with maintaining traceability of local radiological standards to appropriate national standards. In December 1993, PNL was accredited as a Secondary Calibration Laboratory for Ionizing Radiation (SCLIR) through the National Voluntary Laboratory Accreditation Program (NVLAP). This accreditation implies the concurrence by NIST that PNL provides highly accurate instrument calibrations and dosimeter irradiations and that the laboratory complies with NIST Special Publication 812 (U.S. Department of Commerce/National Institute of Standards and Technology 1991). In addition to accurate performance, this document also requires SCLIR to have well qualified personnel, rigorous quality control, and adequate procedures to ensure continued high quality.

The primary source of national standards is the NIST. Reference calibrations are regularly obtained from NIST for those standards requiring a high degree of precision. Calibrations are also obtained from other reference laboratories, such as a source manufacturer, for less critical work. When NIST has been unable to provide a needed service, reference calibrations have been obtained from foreign standards laboratories such as the Physikalisch-Techische Bundesanstal in the Federal Republic of Germany; however, the NIST is always consulted before establishing relationships under these special circumstances.

\subsection{Quality Assurance Program}

Quality assurance (QA) is defined as planned and systematic actions necessary to provide adequate confidence that an item or facility will perform satisfactorily in service. Establishing and implementing a QA program in conformance with DOE policy (DOE Order 5700.6A) is essential. All measurement and test equipment is assigned a calibration level: level 1 is assigned to local standards calibrated by qualified standards or neutral laboratories, such as NIST; level 2 is assigned to equipment calibrated in-house using the level 1 equipment and to tasks where it is necessary to establish traceability of the final measurement; level 3 is assigned to equipment used for indication only. A piece of equipment is labeled and tracked through a card file system and a Hewlett Packard 9000 data base. The major responsibility for QA has been assigned to a specialist dedicated to this particular task.

In addition, several major programs use QA coordinators to ensure that special needs are met. Training and retraining programs have been established for project workers. Work procedures are prepared when appropriate and are available to project workers. Certification of traceability for level 1 equipment is maintained on file. A QA support system provides for the routine use of measurement and test equipment, such as beam monitors, laser alignment equipment, automatic timers, and datalogger/process-control computers that are required for facility calibration work. Documentation and recordkeeping practices are extensive and are considered important components of the QA program. 


\subsection{Local Standards and Traceability Program}

Maintaining radiological reference fields traceable to national standards is a primary goal of PNL programs. Traceability means adopting some method of ensuring that calibration fields are established and used consistently with national standards. There are two acceptable consistency measurements commonly used to infer traceability: 1) implied consistency, which is established through the use of a laboratory standard submitted to NIST for calibration within radiation fields applicable to the laboratory, and 2) demonstrated consistency, which is established through a measurement quality assurance (MQA) interaction with NIST. This latter method is akin to a performance test administrated by NIST and is instrumental in verifying measurement traceability, as opposed to simply obtaining or maintaining a traceable source or reference instrument (i.e., artifact traceability). The disadvantage of traceability based only on implied consistency is the lack of demonstration, demonstration would indicate that measurements made of traceable sources or using traceable reference instruments are consistent with those made using national standards. Traceability based on demonstrated consistency provides some assurance that traceable instruments and/or sources are being used properly - whether it be to calibrate additional sources (or reference fields) or laboratory instrument standards-such that traceability is appropriately extended as desired.

The NIST supports the use of both techniques in maintaining traceability, but favors the practice of performing MQA interactions on a routine basis coupled with providing infrequent instrument or source calibrations. The Radiological Standards and Calibration Laboratory has adopted the NIST philosophy and has sought to implement it whenever possible.

\subsection{Computer and Data Management Facilities}

All pertinent data relating to instrument and/or source calibrations conducted at the Radiological Standards and Calibration Laboratory are documented and stored in an electronic data base using a dedicated Hewlett Packard (HP) 9000 computer. The hierarchical HP data base IQERRY is currently used to record the calibration results obtained by all laboratory activities. However, changing and growing demands on Site calibration services have created difficulties for this highly structured data base. As a result, new and much more flexible data base options are currently being evaluated in order to upgrade the laboratory's data management system. 


\section{Appendix A}

\section{Photographs of the Radiological Standards and Calibrations Laboratory}




\section{Appendix A}

\section{Photographs of the Radiological Standards and Calibrations Laboratory}

The appendix is a compilation of photographs that illustrate facilities located within the Radiological Standards and Calibrations Laboratory. the photographs are arranged in groups, and each group is proceeded by a brief description.

Figures A.1 and A.2 pertain to Section 2.1, Calibration Laboratory Layout.

Figures A.3 through A.6 illustrate the material in subsection 2.2.1, Low-Scatter Room.

Figures A.7 and A.8 relate to the source well room, which is described in subsection 2.2.2.

Figures A.9 through A.13 pertain to subsection 2.2.3, X-Ray Facilities and Capabilities.

Figures A.14 and A.15 correspond to the material presented in subsection 2.2.4, High-Exposure Facility.

Figure A.16 depicts a portion of the BETA Standards Laboratory described in subsection 2.2.5.

Figure A.17 through A.23 pertain to the ANSI Testing Laboratory described in subsection 2.2.7.

Figure A.24 depicts the Instrument Repair Shop, which is described in subsection 2.2.8.

Figures A.25 through A.29 illustrate the Thermolumenescence Dosimetry Laboratory described in subsection 2.2.9.

A. 1 

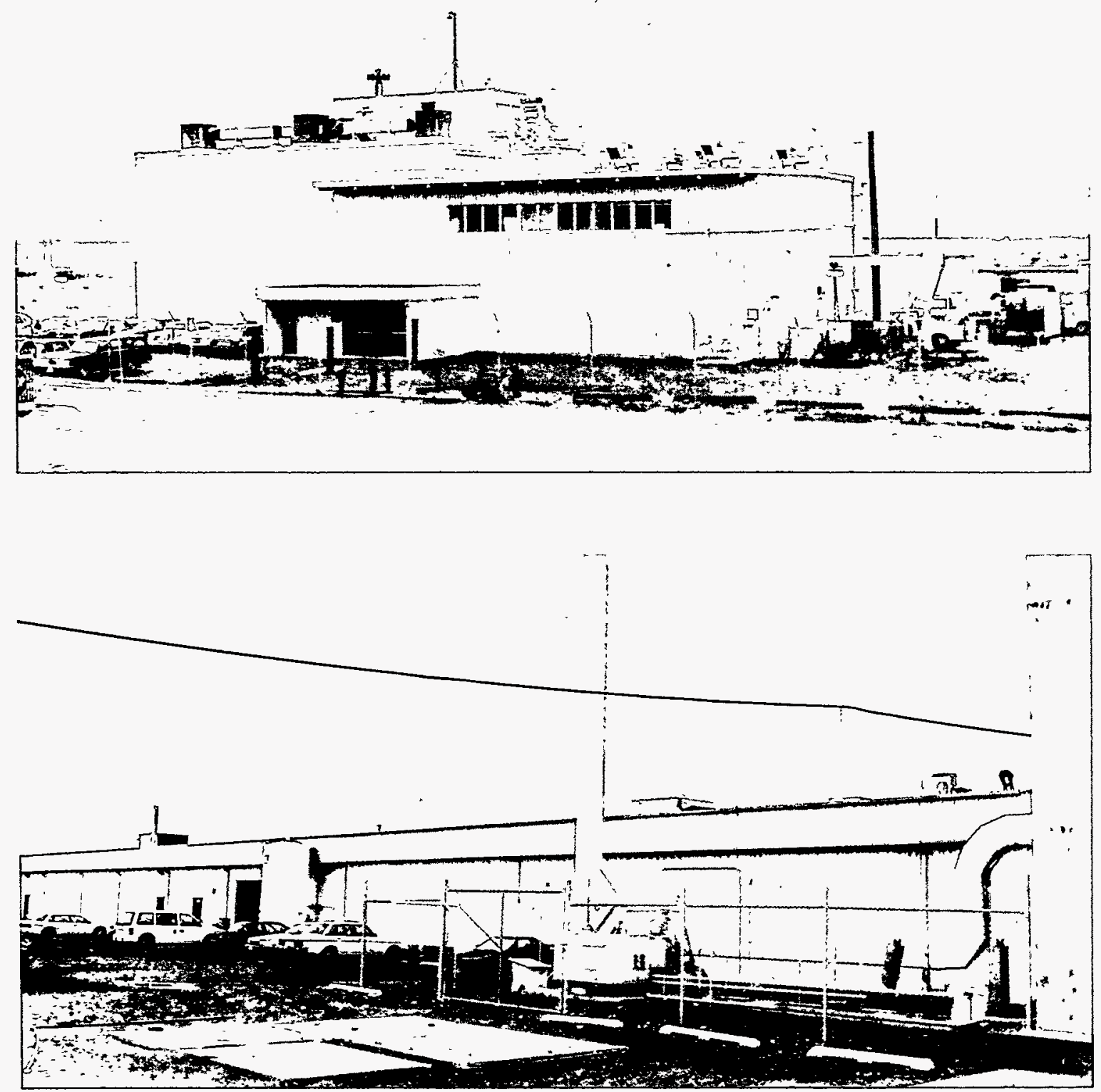

Figure A.1. Radiological Standards and Calibration Laboratory: A) foreground, original reactor and associated office building; background, Phase II building addition and adjoining instrument shop trailer. B) Phase I and Phase III, south-wing building additions. 


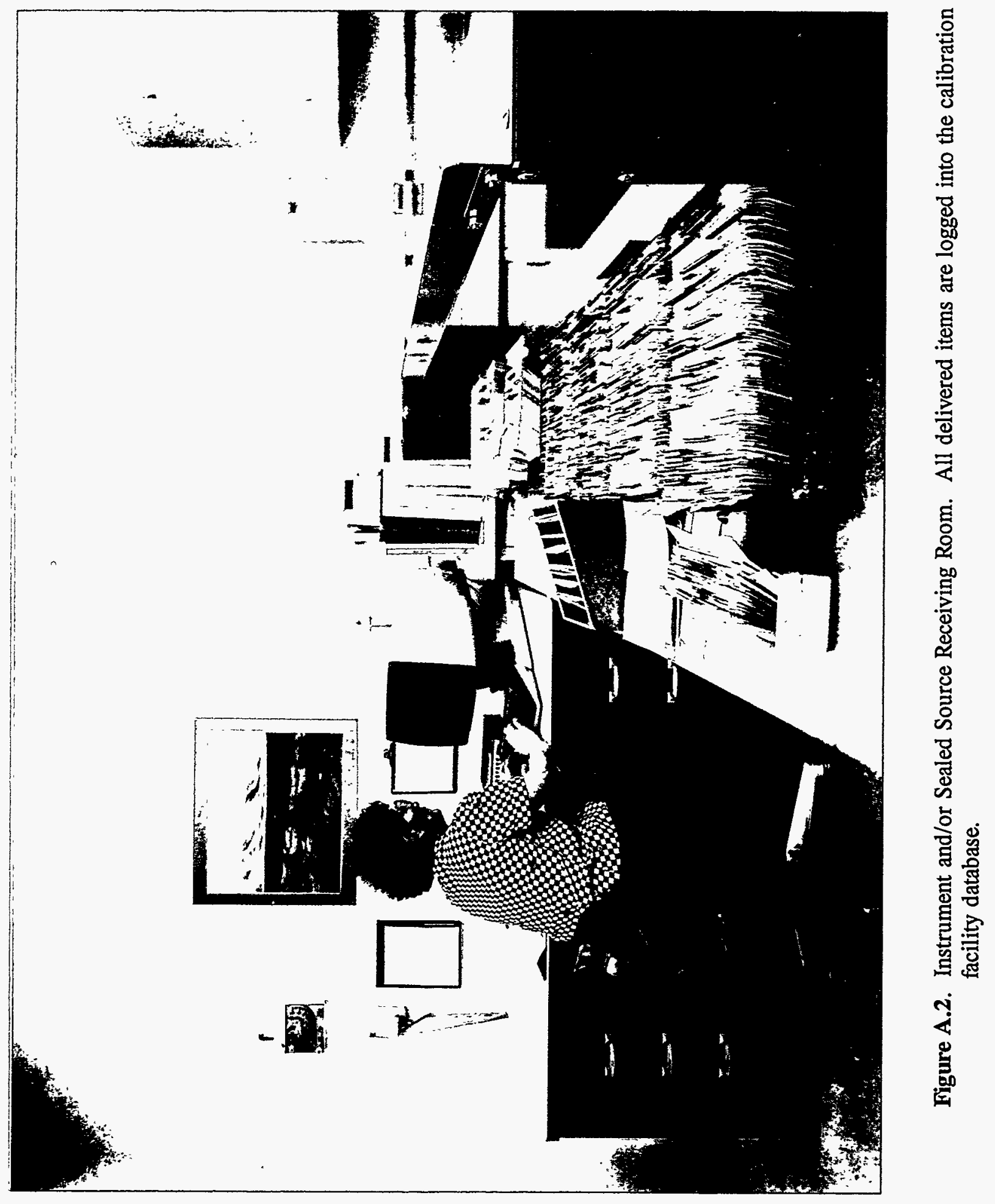

A. 3 


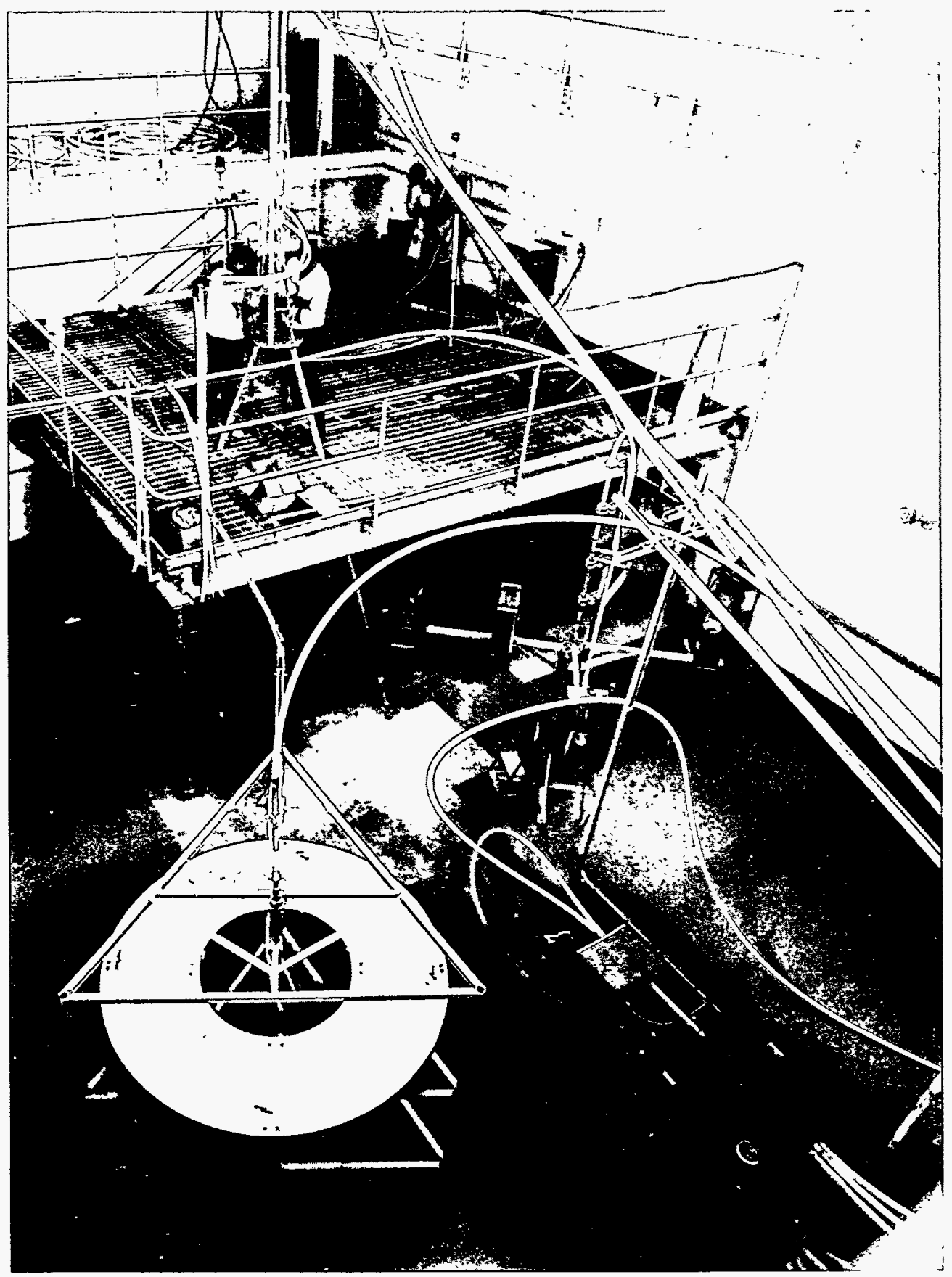

Figures A.3. The Laboratory's Low-Scatter Room. This station is suitable for neutron and photon irradiation of devices that may be sensitive to scattered radiation. The facility is equipped with two irradiation stations. The position shown at lower left is predominantly used for photon irradiations of personnel dosimeters using either ${ }^{137} \mathrm{Cs}$ or ${ }^{60} \mathrm{Co}$ sources. The position shown at the upper left is located near the geometric center of the room and is used for neutron irradiations. 


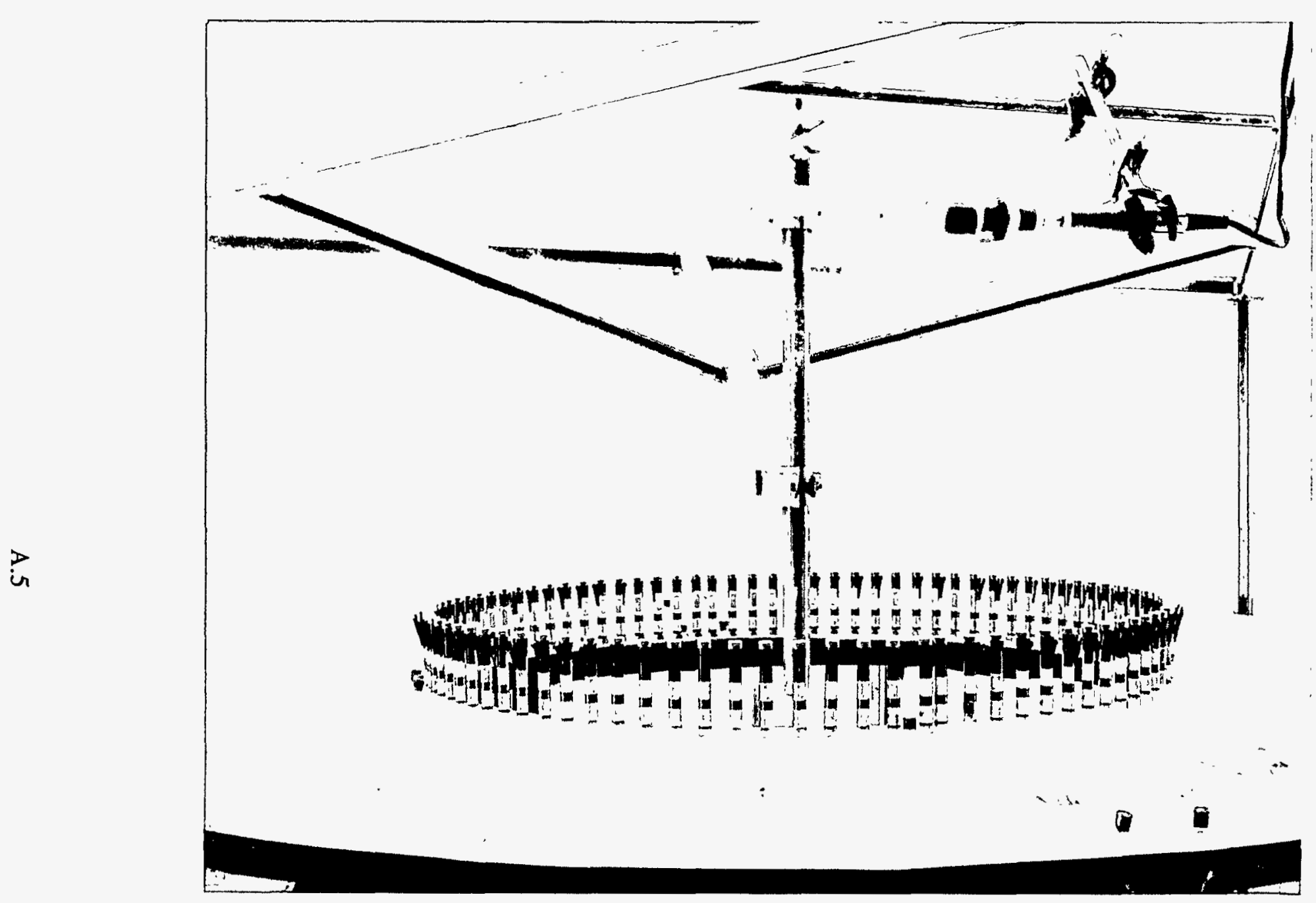

Figure A.4. Within the Low-Scatter Room, This Floor-Level Station is Used for Photon Irradiations. Dosimeters may be placed at distances from 50 to $100 \mathrm{~cm}$ from the source position. The supporting structure is composed of low atomic number materials and is rigid enough to prevent warping. With available jigs, dosimeters may be placed at equal distances in a circumference around the source position. An air ionization chamber is available for monitoring irradiation quality. 


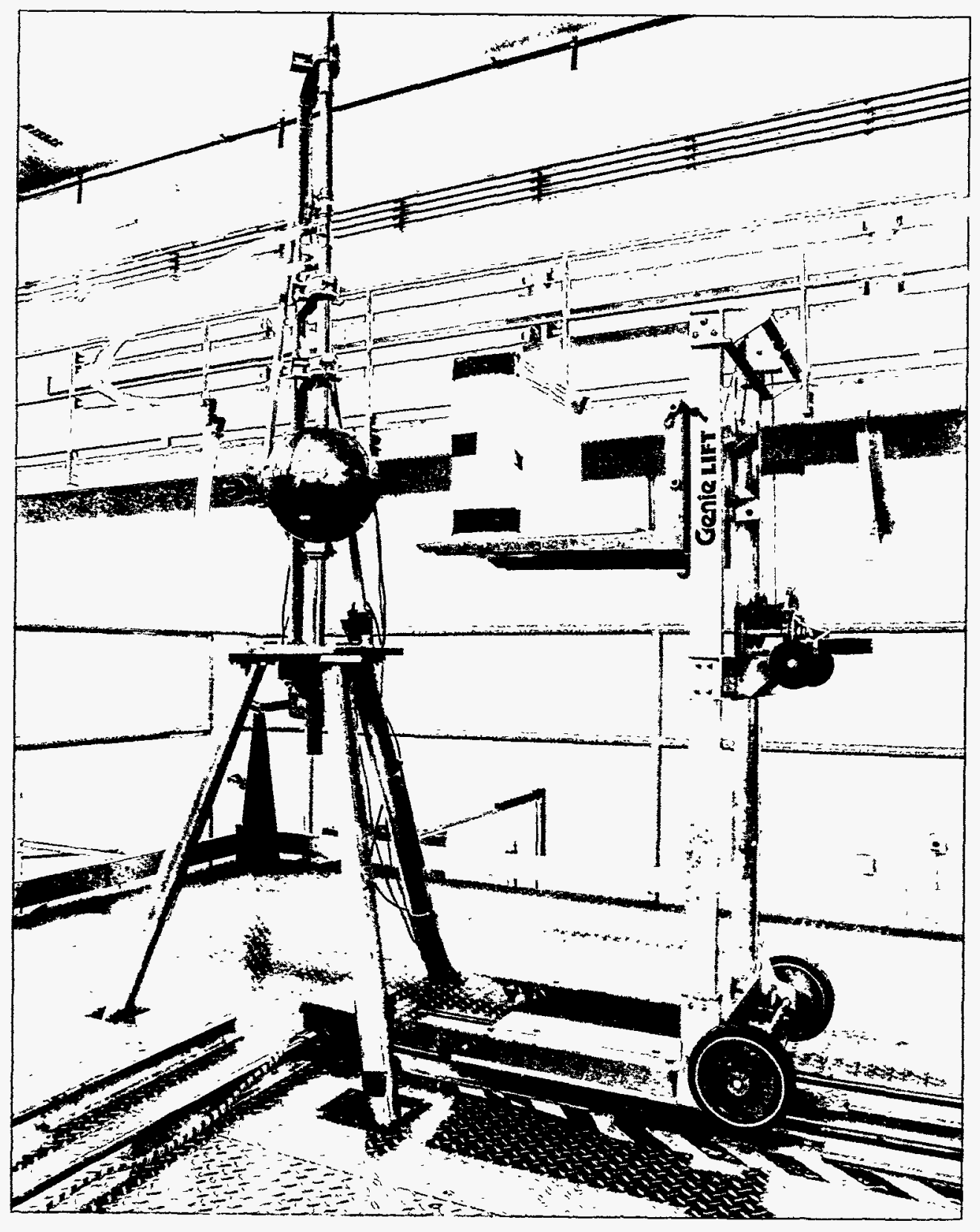

Figure A.5. The Low-Scatter Room Tower Irradiation Position, Which Allows Irradiations Using Photon or Neutron Sources. Neutron irradiations may be performed with either a bare source configuration or using a moderator assembly, such as the cadmium-covered $\mathrm{D}_{2} \mathrm{O}$ sphere shown here. While most dosimeters are irradiated at a distance of $50 \mathrm{~cm}$ from the source, instrument calibrations are accommodated by a flexible positioning system, which has a range extending to about $3 \mathrm{~m}$ from the source. Although the scatter contribution is minimized in this facility, room return evaluations and appropriate corrections are made to ensure instrument calibrations are normalized to free field conditions. 


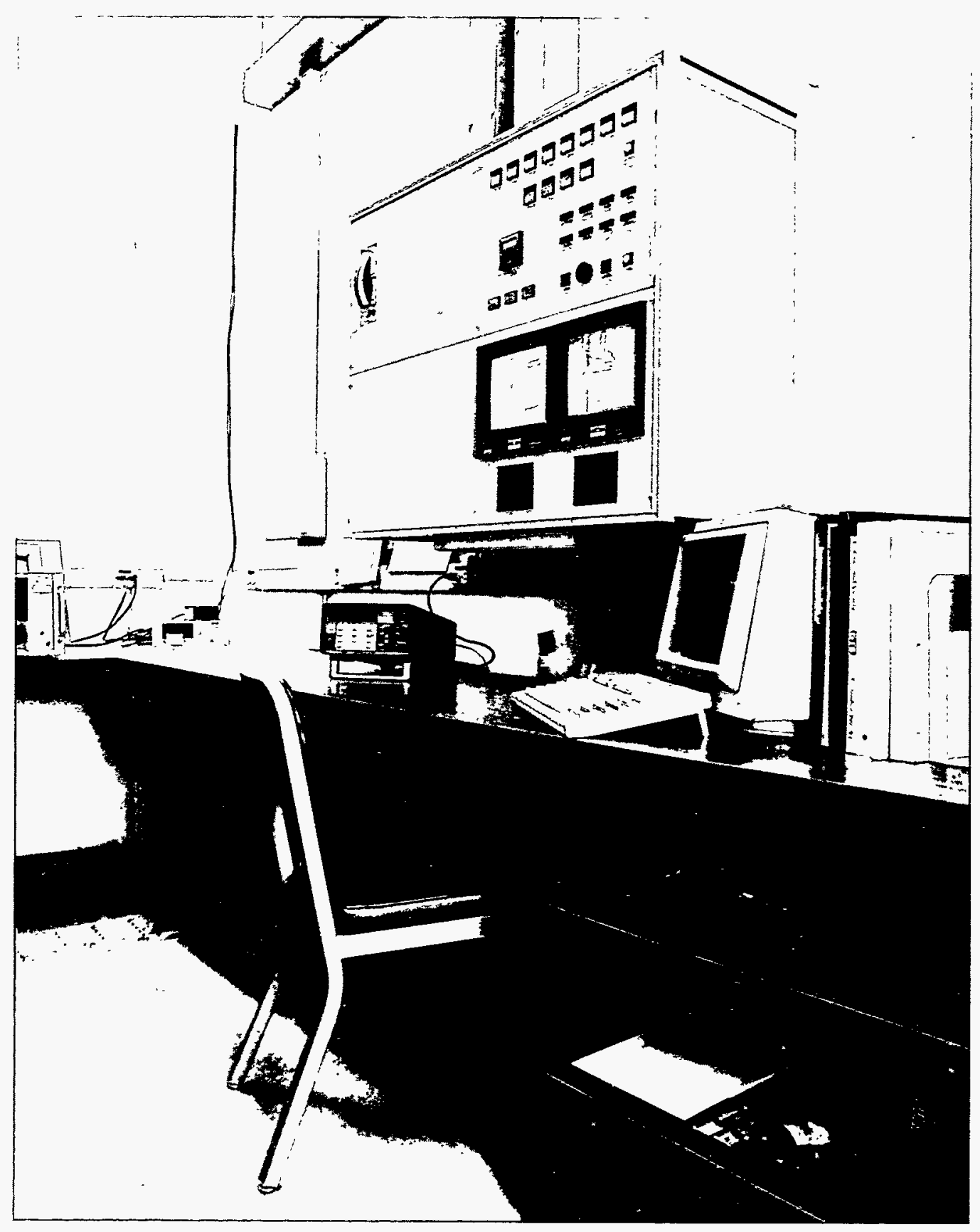

Figure A.6. Remote Control Panel Within the Low-Scatter Room. All sources in the low-scatter room are stored in wells that extend about $30 \mathrm{ft}$ into the ground outside the facility. The sources are accessed and replaced using a pneumatic transfer system that is remotely controlled from panel shown above. Quality control chambers, source placement indicators, and camera equipment are also monitored from this position, which is located adjacent to, but outside of, the 2 -ft-thick concrete walls enclosing the facility. 


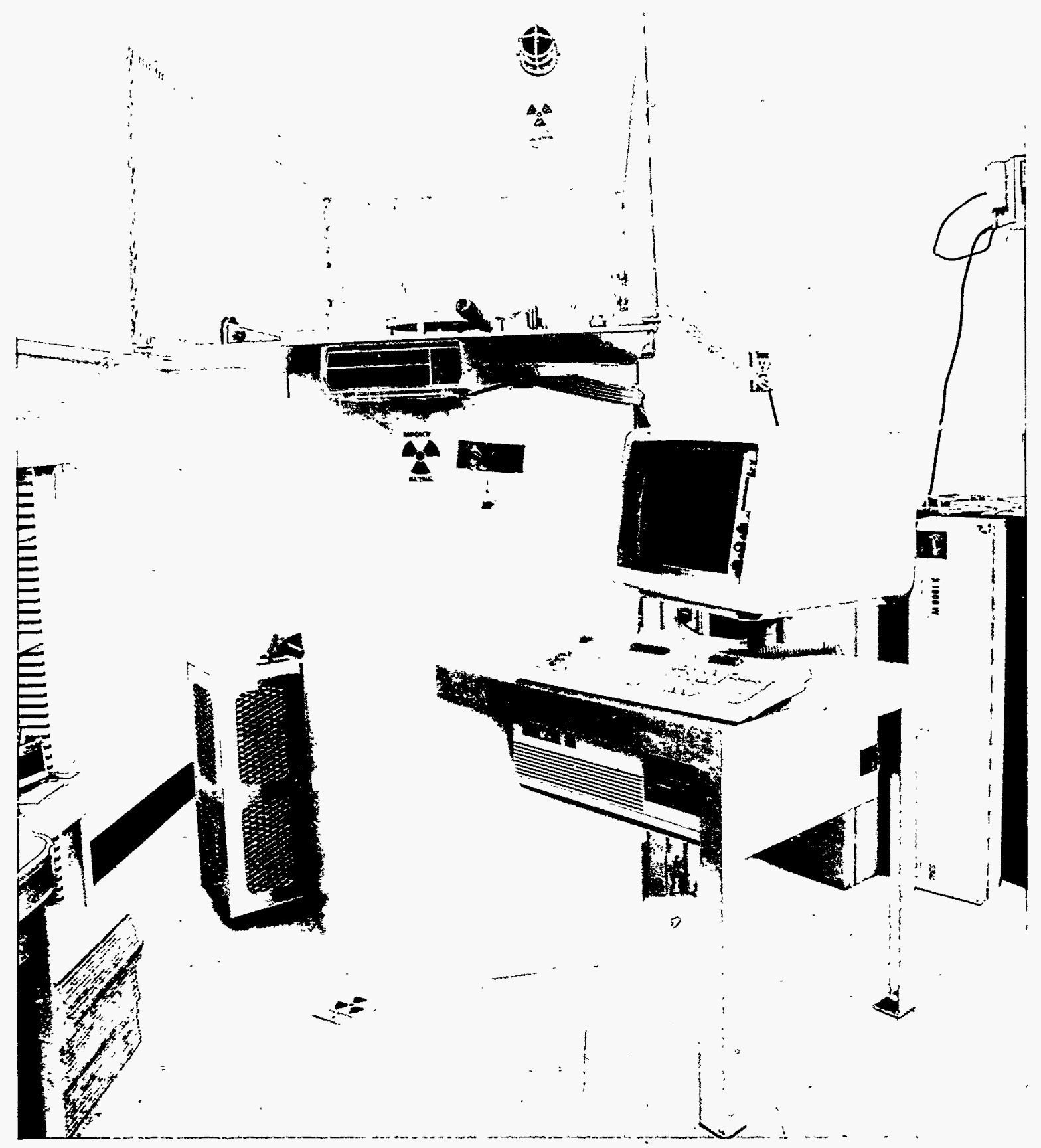

Figure A.7. Automated Source Well 4, Which Contains ${ }^{60} \mathrm{Co}$. This well produces radiation fields covering exposure rates from $20 \mathrm{mR} / \mathrm{h}$ to $4.6 \mathrm{R} / \mathrm{h}$. 


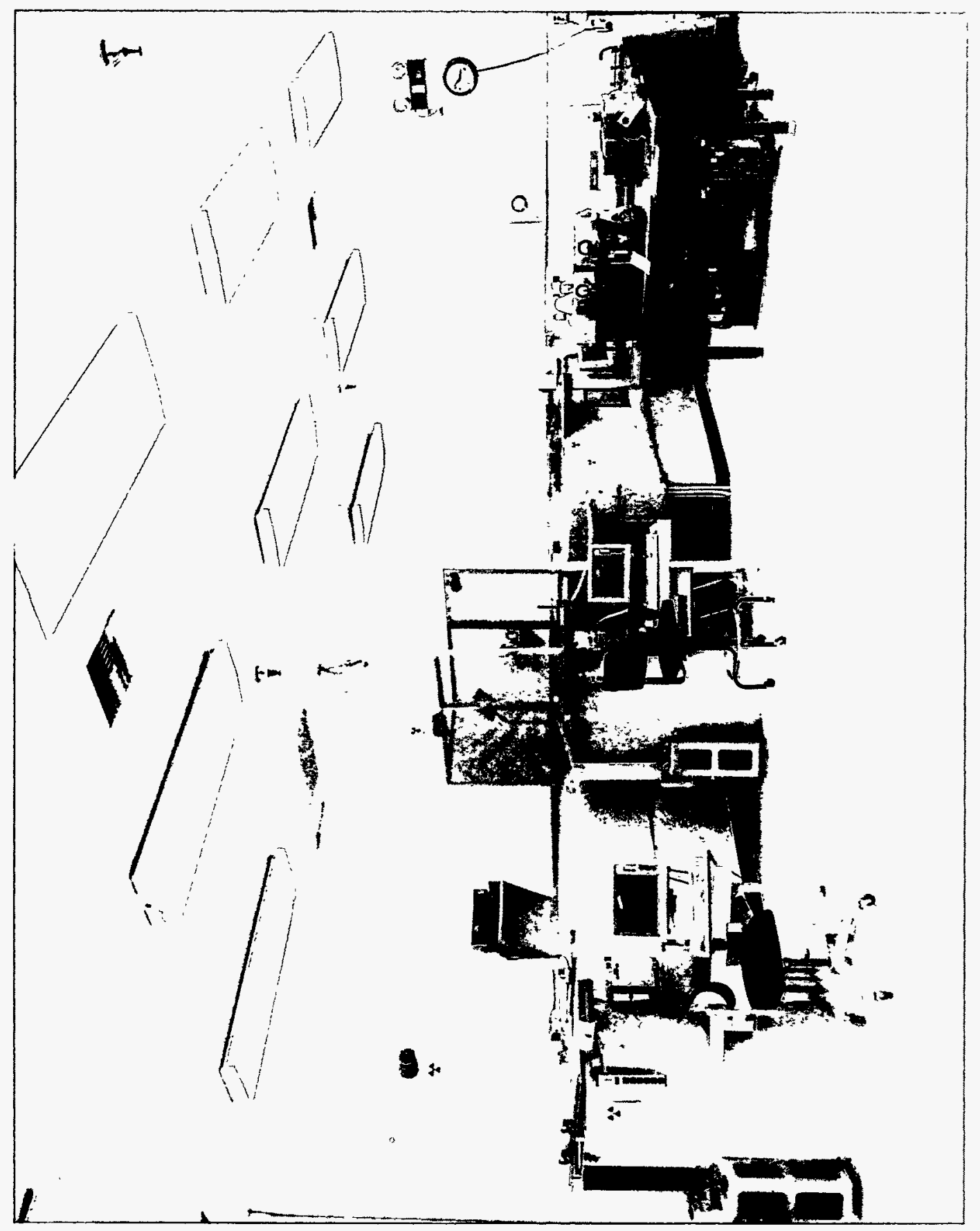

总

咆

옹

옹요

क

ญ्.

E

4

ฟิ้

.

㐘

m

ขึ

용

ㅁo 8

菉苛

인

형

-

离

¿

官 을

䏯

告

A. 9 


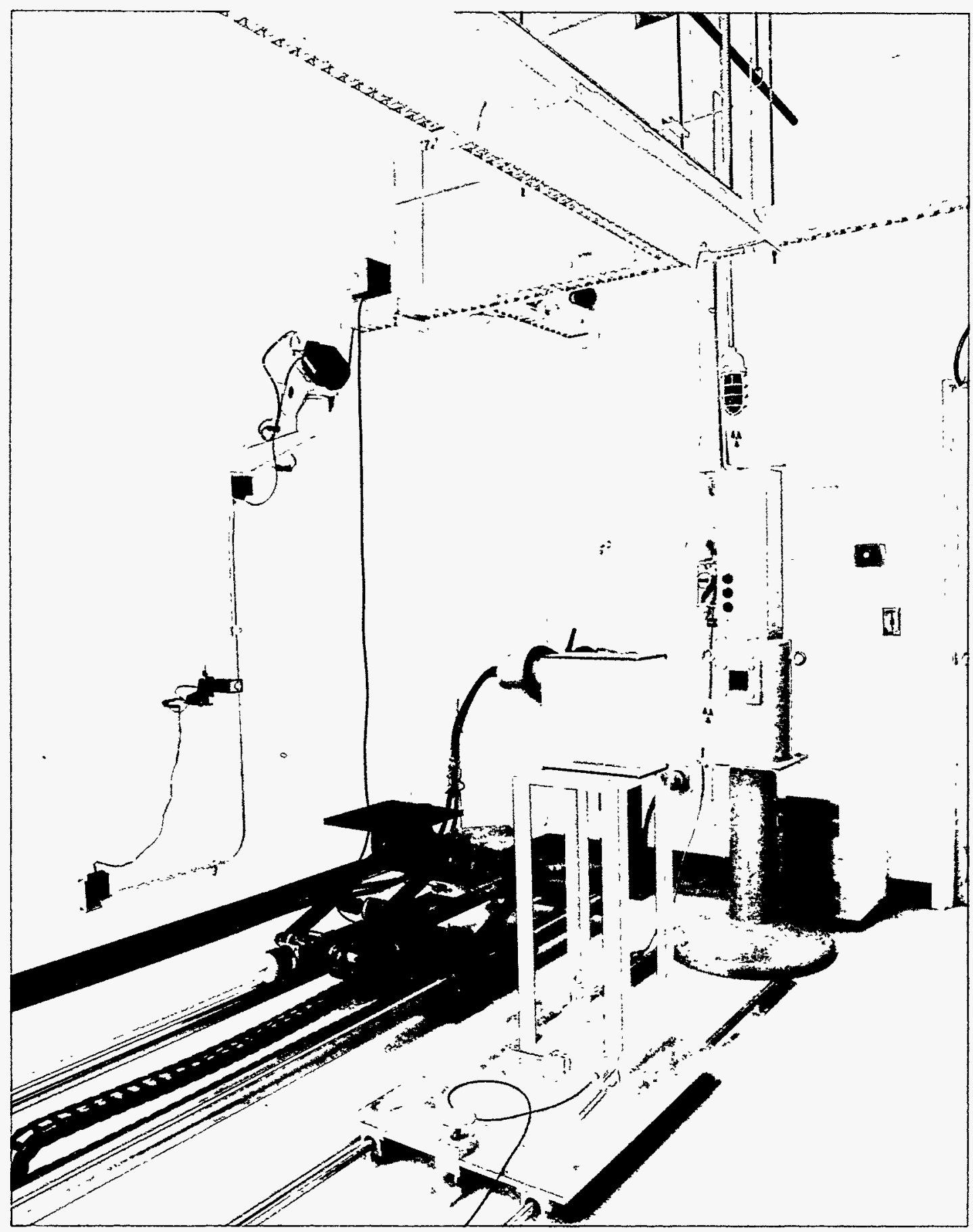

Figure A.9. J. L. Shepherd Model $81,100-\mathrm{Ci}{ }^{137} \mathrm{Cs}$ Irradiator (right). This equipment is available for performing dosimeter irradiations or instrument calibrations up to a distance of $4 \mathrm{~m}$. A Pantak Model HF320C x-ray machine (left) is available for generating NIST- and ISObeam techniques. The associated $x$-ray irradiation platform is capable of rotating and can be used to perform static and dynamic angular response studies. 


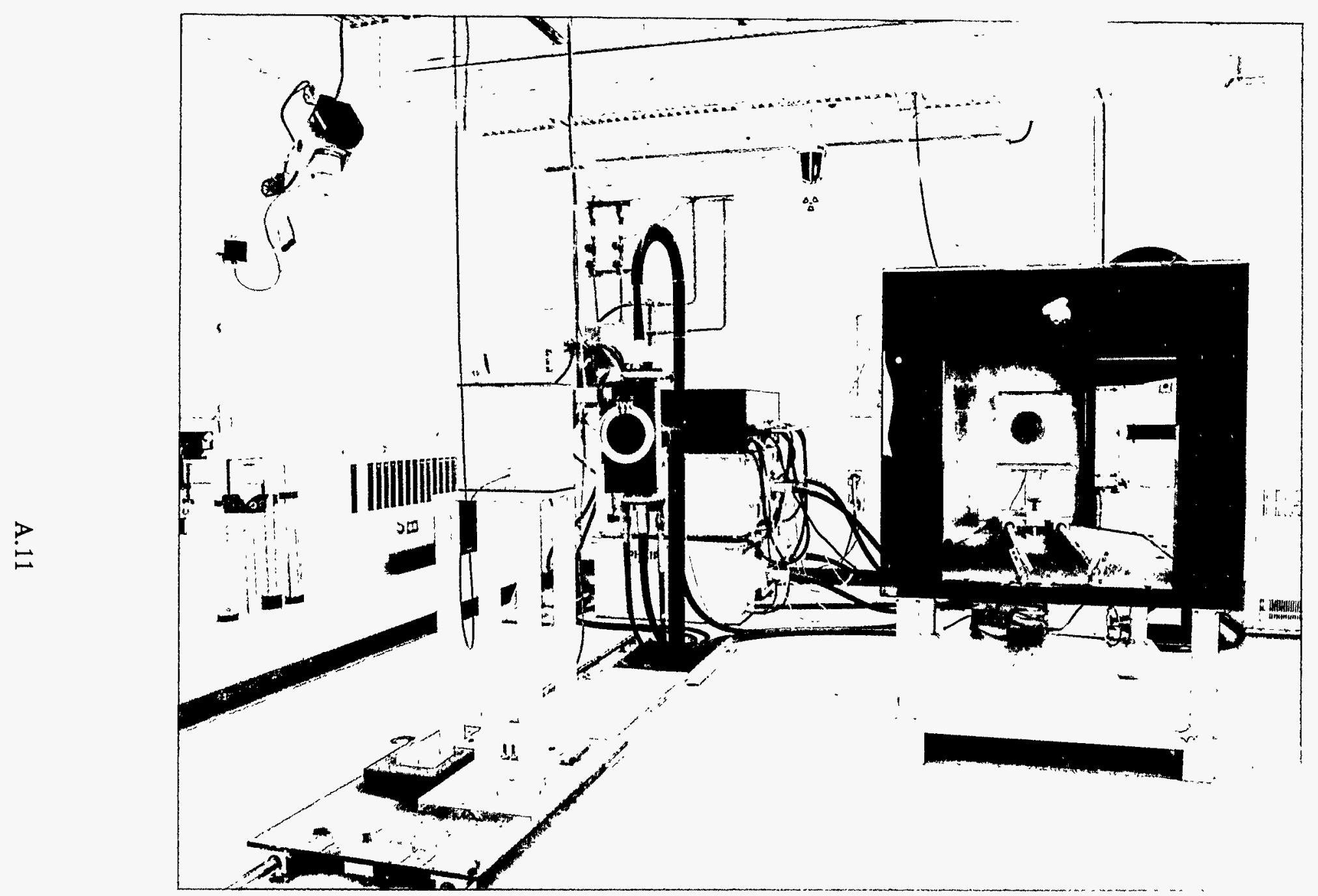

Figure A.10. Two Philips Model 324 X-Ray Units. Both are available for performing various dosimeter irradiations and instrument response evaluations. The unit on the left is configured to produce most NIST- and several ISOtechniques. The unit on the right is used for generating K-fluorescence techniques, which are useful for specific photon energy response evaluations from energies as low as $8.6 \mathrm{keV}$ to $59.3 \mathrm{keV}$. 


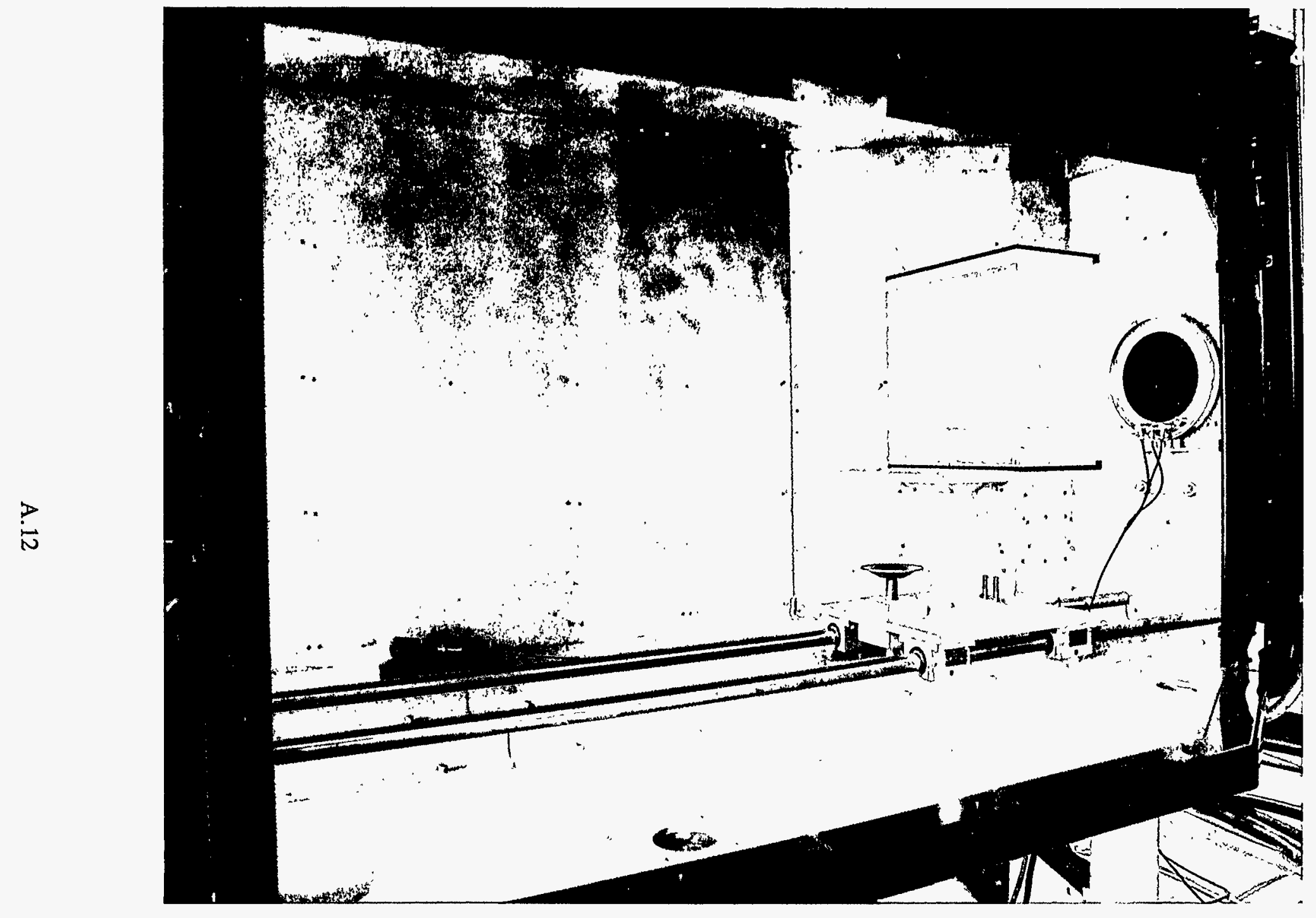

Figure A.11. Philips Model $324 \mathrm{X}$-Ray Machine. K-fluorescence beams are extracted at a $90^{\circ}$ angle from the incident $\mathrm{x}$-ray beam direction. A special shielded enclosure is used by PNL to maintain "clean" spectra. 


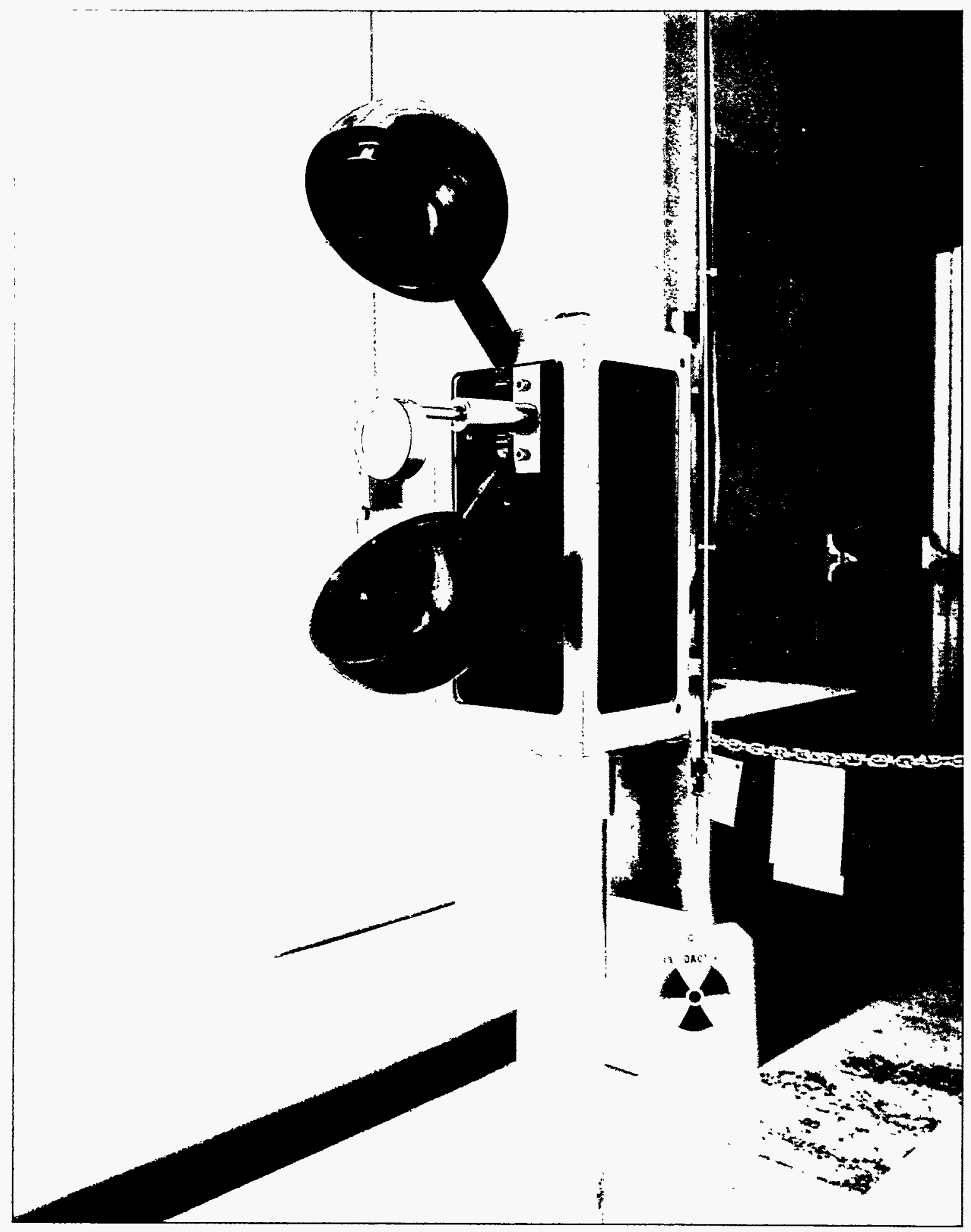

Figure A.12. An ${ }^{241} \mathrm{Am}$ Source, Which Provides a Photon Calibration Field in the 60-keV Energy Range

A. 13 


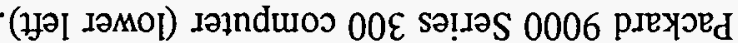
\#!

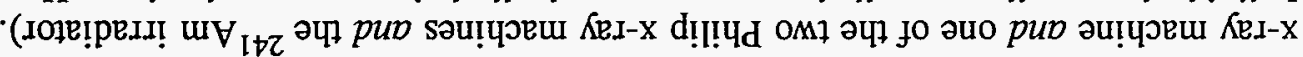

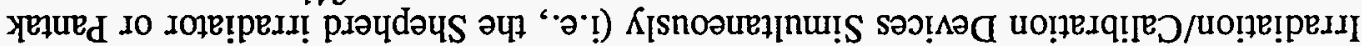

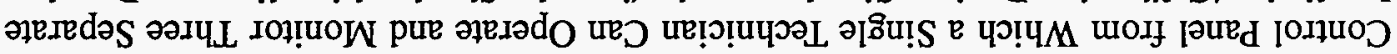

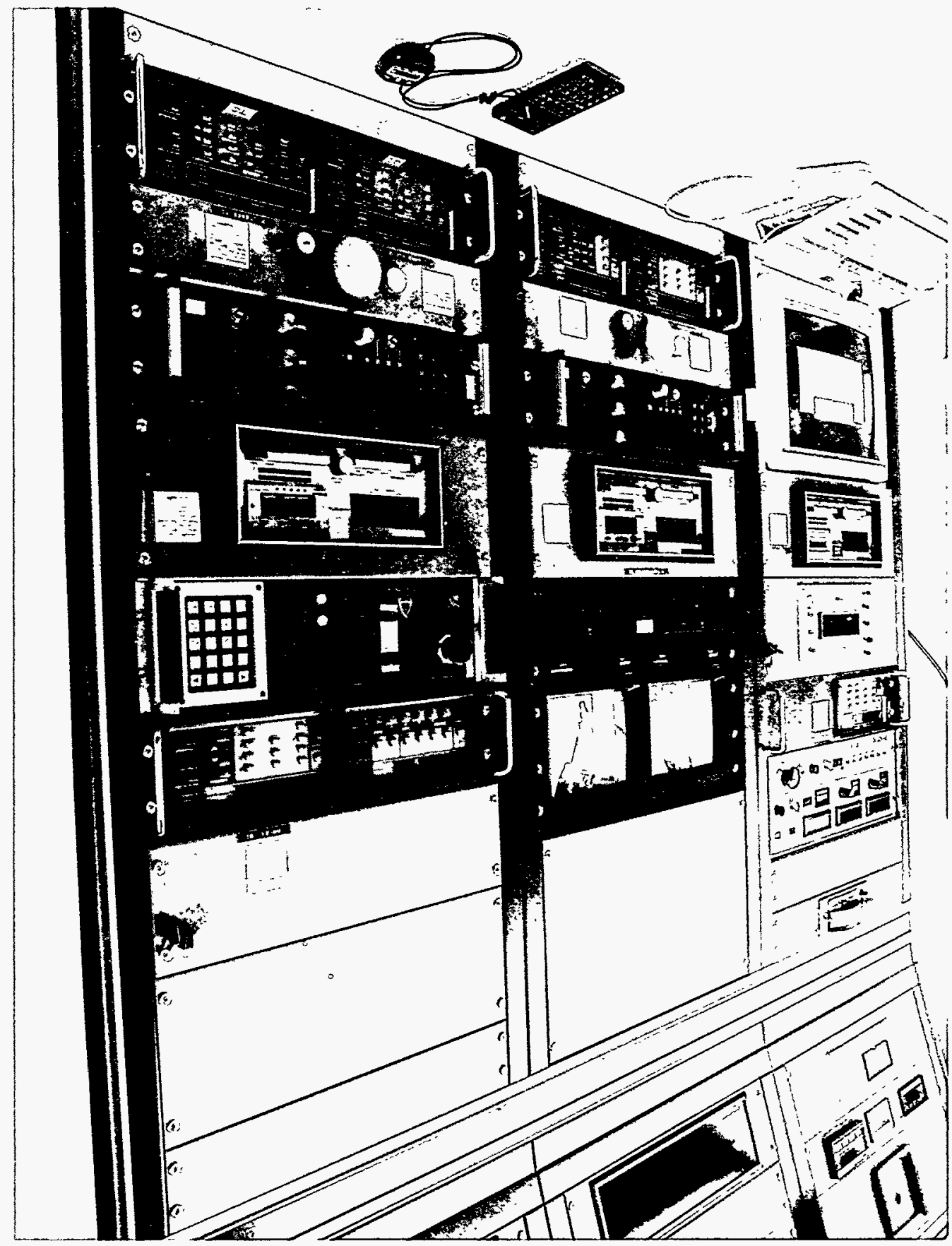




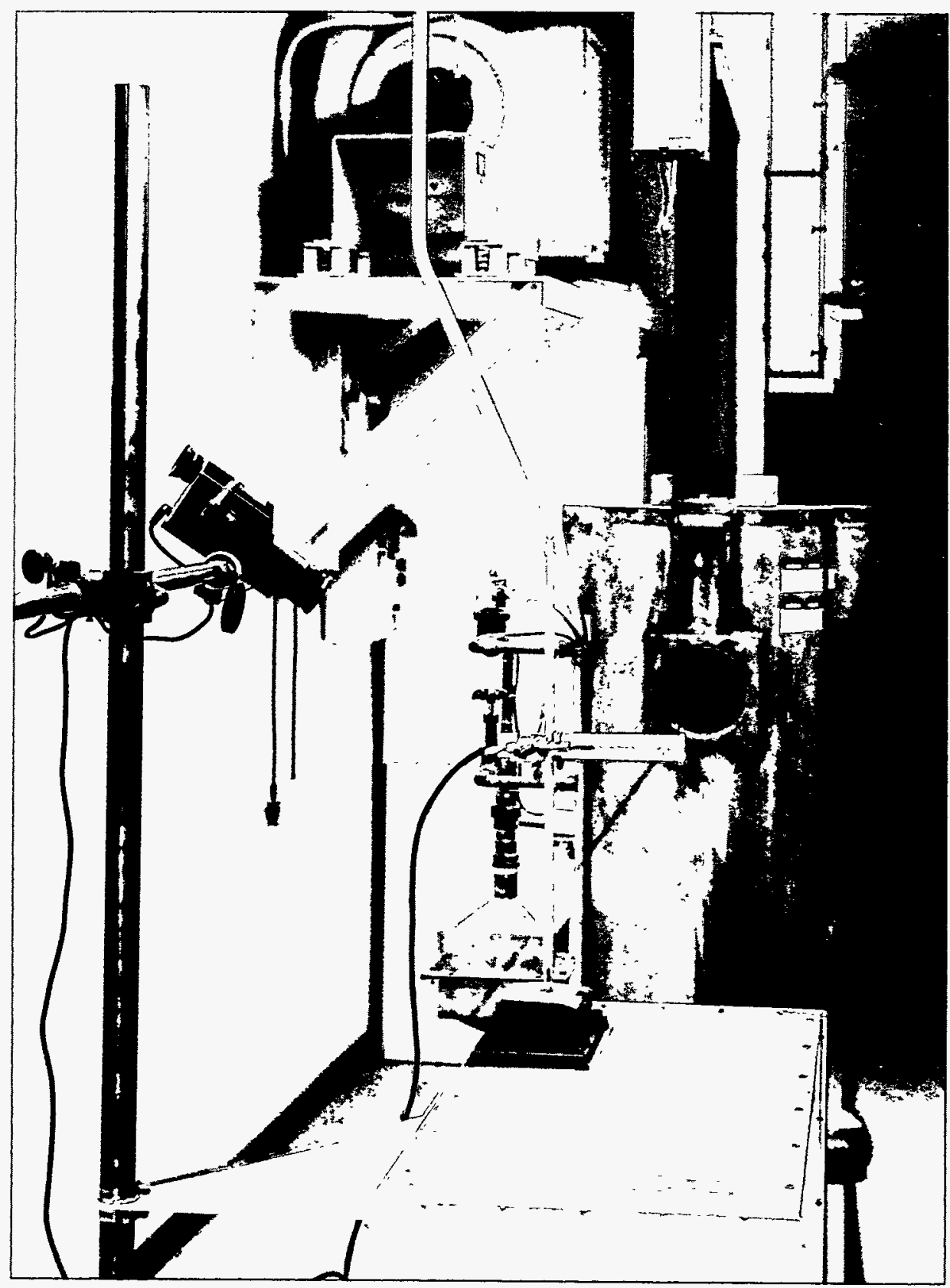

Figure A.14. The High-Exposure Facility is Used for High-Level ${ }^{137} \mathrm{Cs}$ and ${ }^{60} \mathrm{Co}$ Photon Irradiations and Calibrations. The irradiation unit pneumatically lifts the applicable source into the irradiation position. The useful radiation field is collimated in the direction of a wall radiation until instruments or dosimeters are placed near the distant end of the range. This facility is equipped with positioning lasers that aid initial set-up of dosimeters or instruments within the central beam azis at a distance of $1 \mathrm{~m}$. Cameras are positioned to remotely monitor instrument readings during irradiation. 


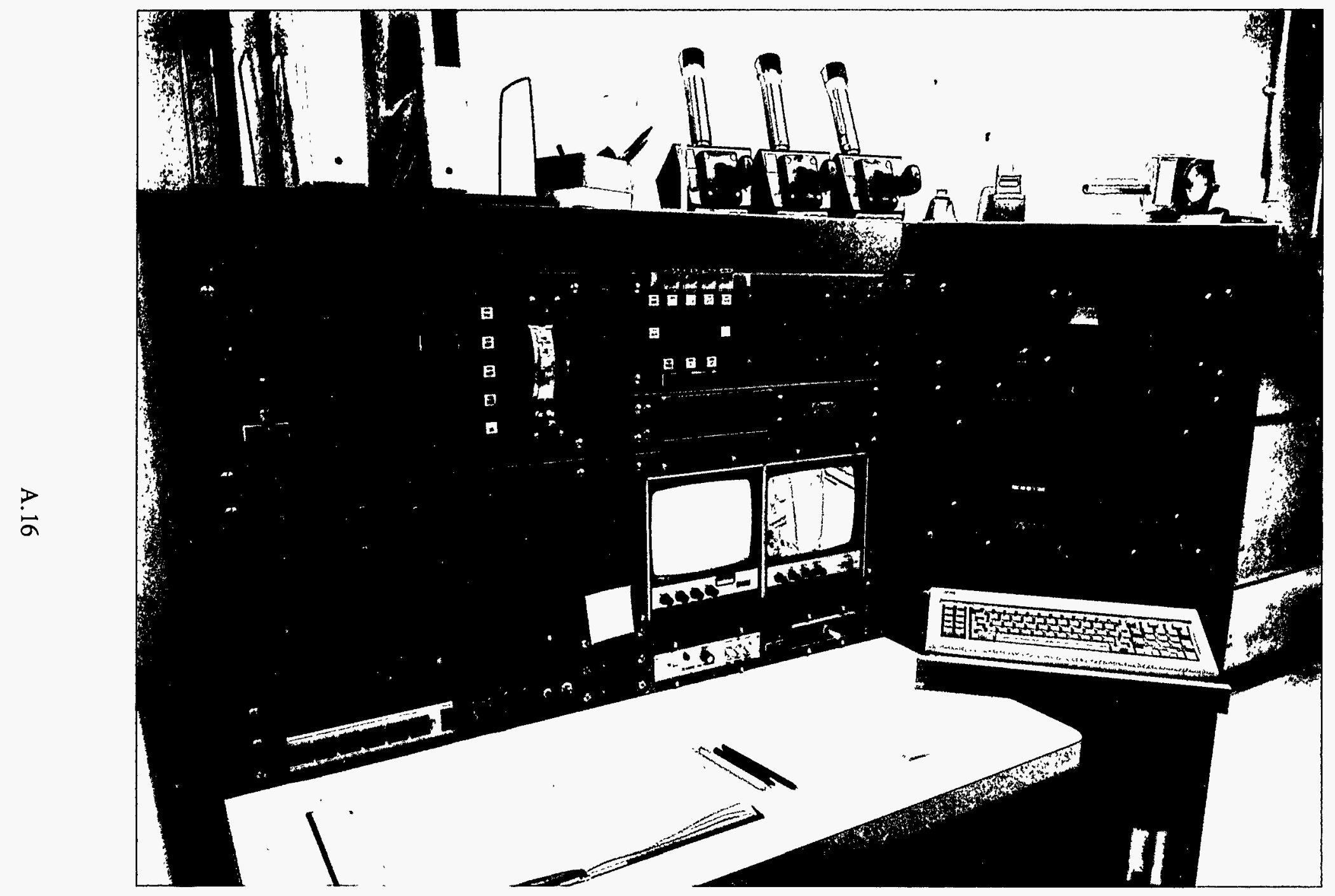

Figure A.15. The High-Exposure Facility Sources Are Remotely Controlled from the Panel Shown Above. This panel also houses the monitors for remote cameras within the radiation area and allows remote positioning of instruments, once the $1-\mathrm{m}$ offset is established using the positioning lasers. 


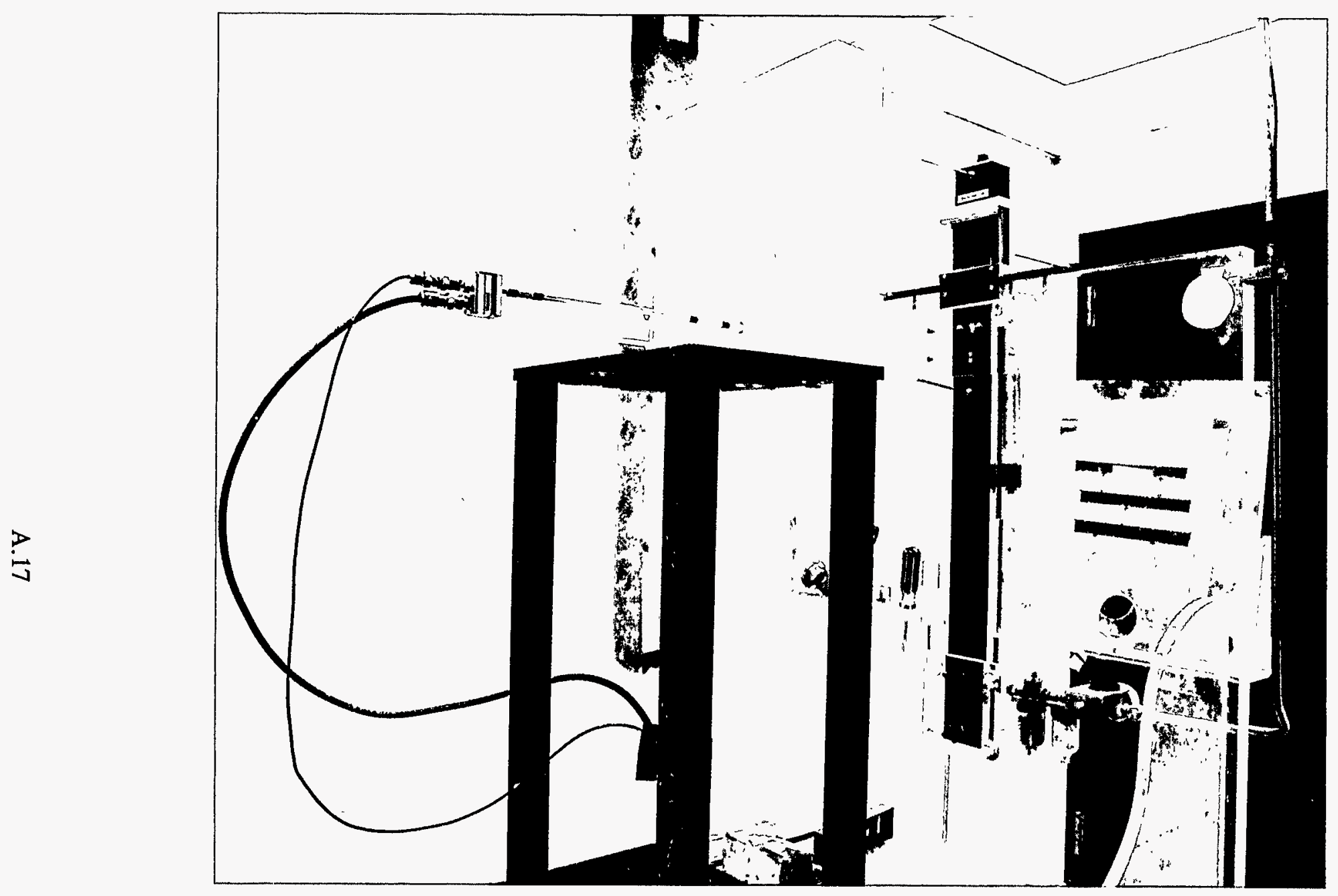

Figure A.16. A Buchler-Amersham Irradiation Jig and Point Source Inventory Are the Basis for PNL's Beta Irradiations. The original apparatus has been modified by replacing the pivot shutter with a pneumatic guillotine shutter. The system has been configured to be computer controlled for automated exposures and to monitor critical quality control information such as temperature, pressure, humidity, and the signal from an ionization chamber mounted in the phantom used for dosimeter irradiations (shown here). 


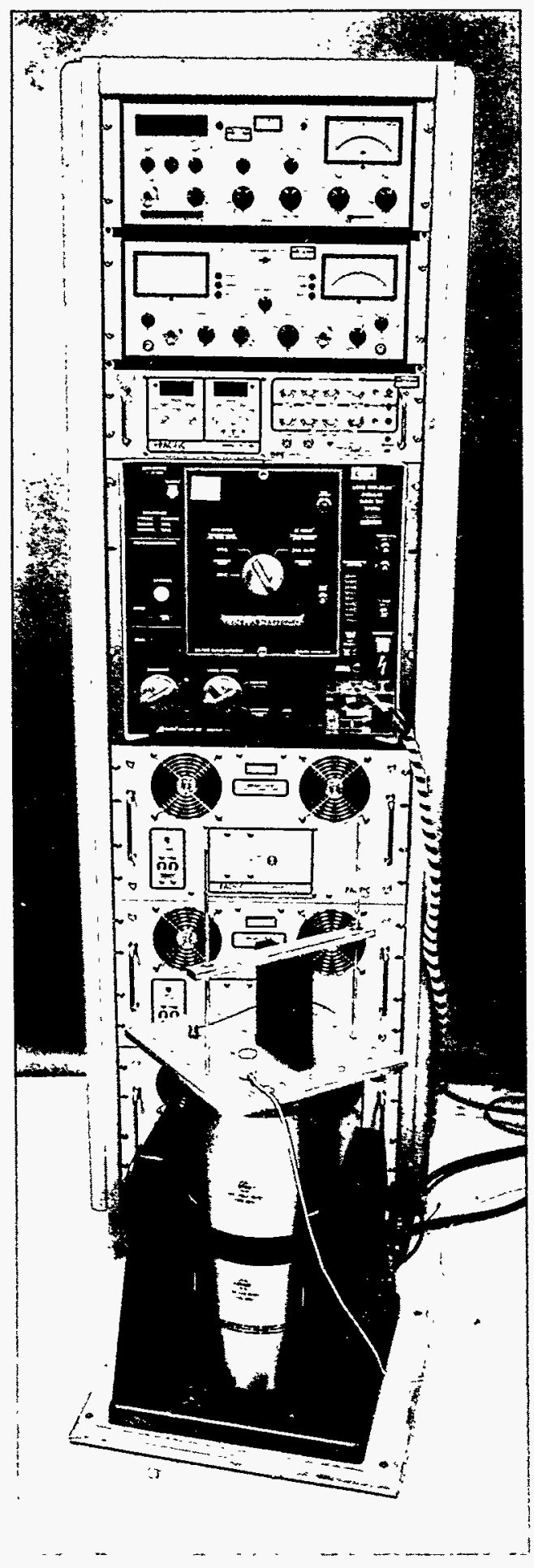

Figure A.17. High-Frequency, High-Acceleration Vibration Table. Also visible in instrument rack are high-voltage transient and line noise generators. 


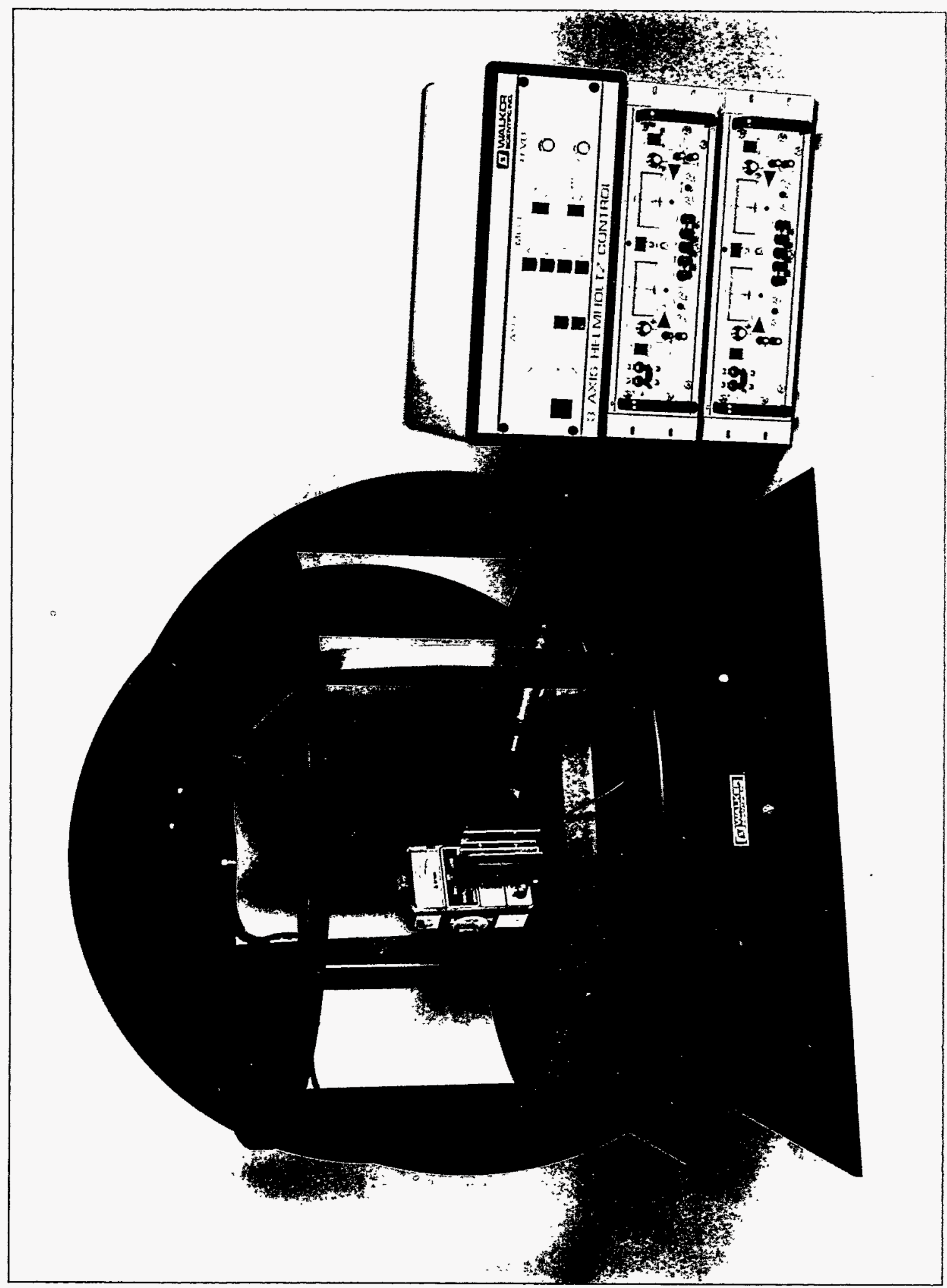

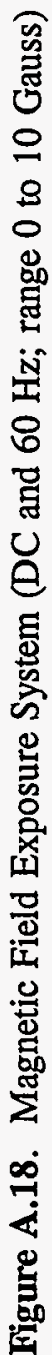

A. 19 


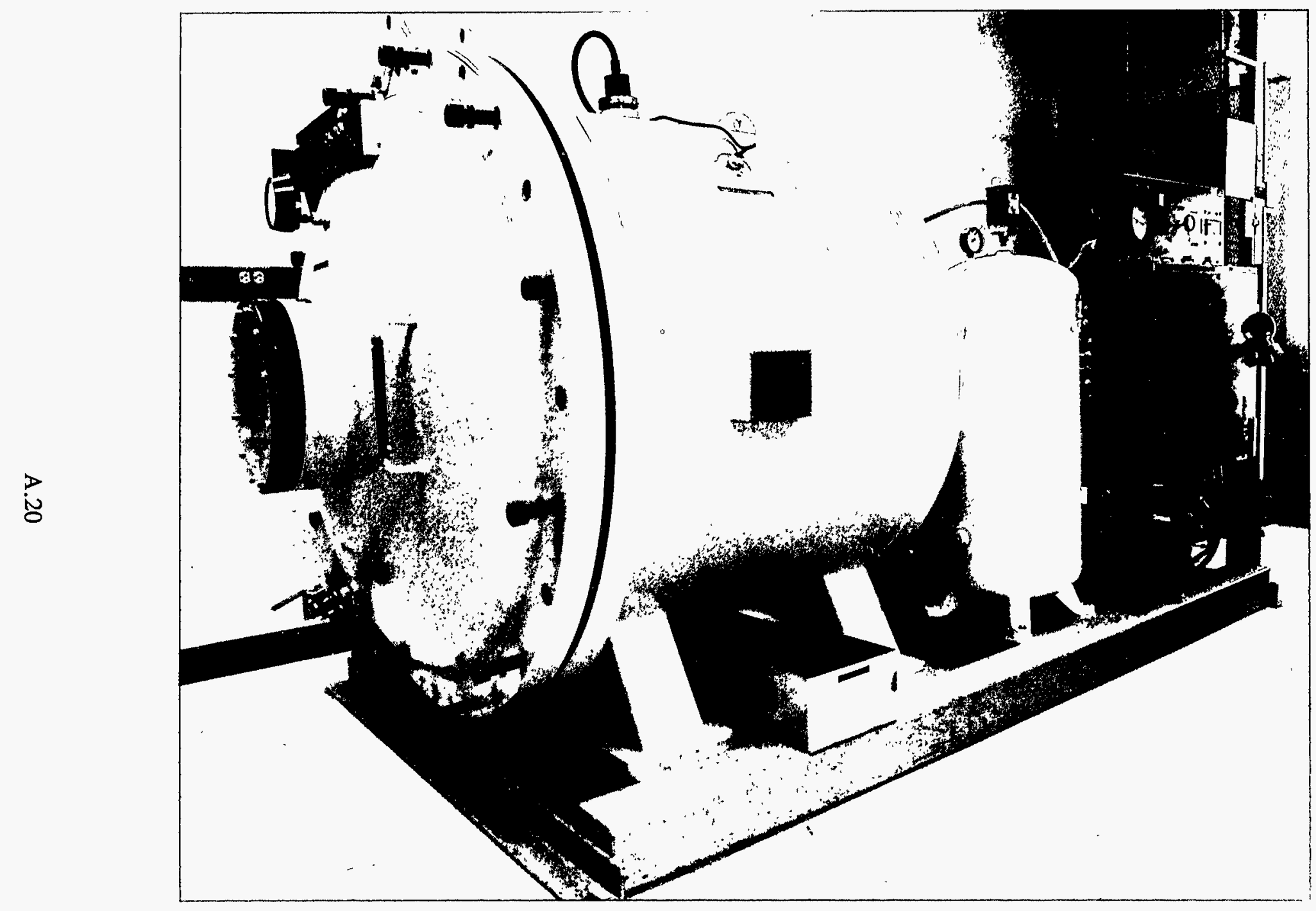

Figure A.19. Pressure/Vacuum Chamber for Simulating Variations in Ambient Pressure Levels (volume: $1.4 \mathrm{~m}^{3}$, range: 200 to $2800 \mathrm{mmHg}$ ) 


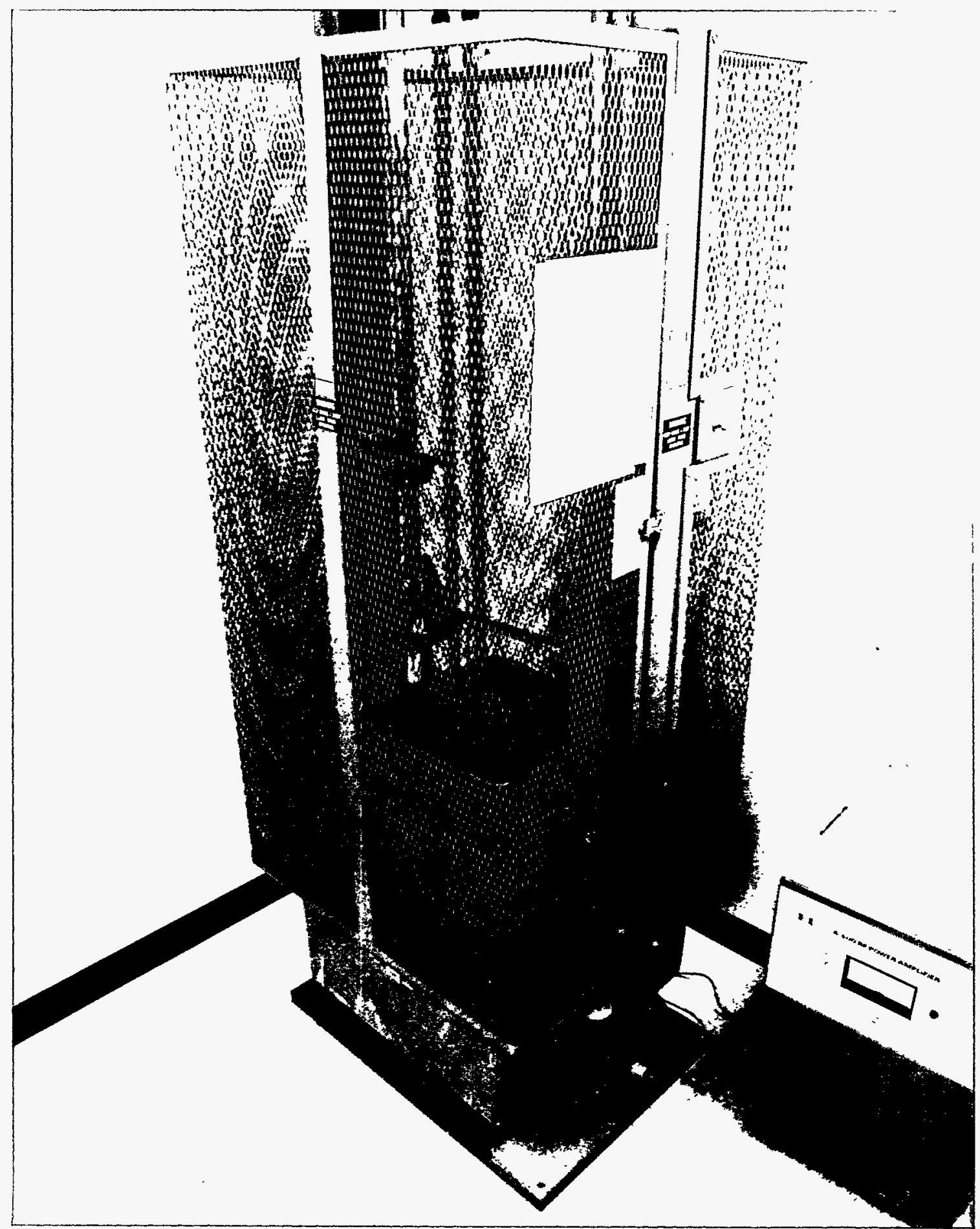

Figure A.20. Mechanical Shock Testing Apparatus (maximum acceleration: $3000 \mathrm{~g}$, maximum test load: $90.7 \mathrm{~kg}$ ) 


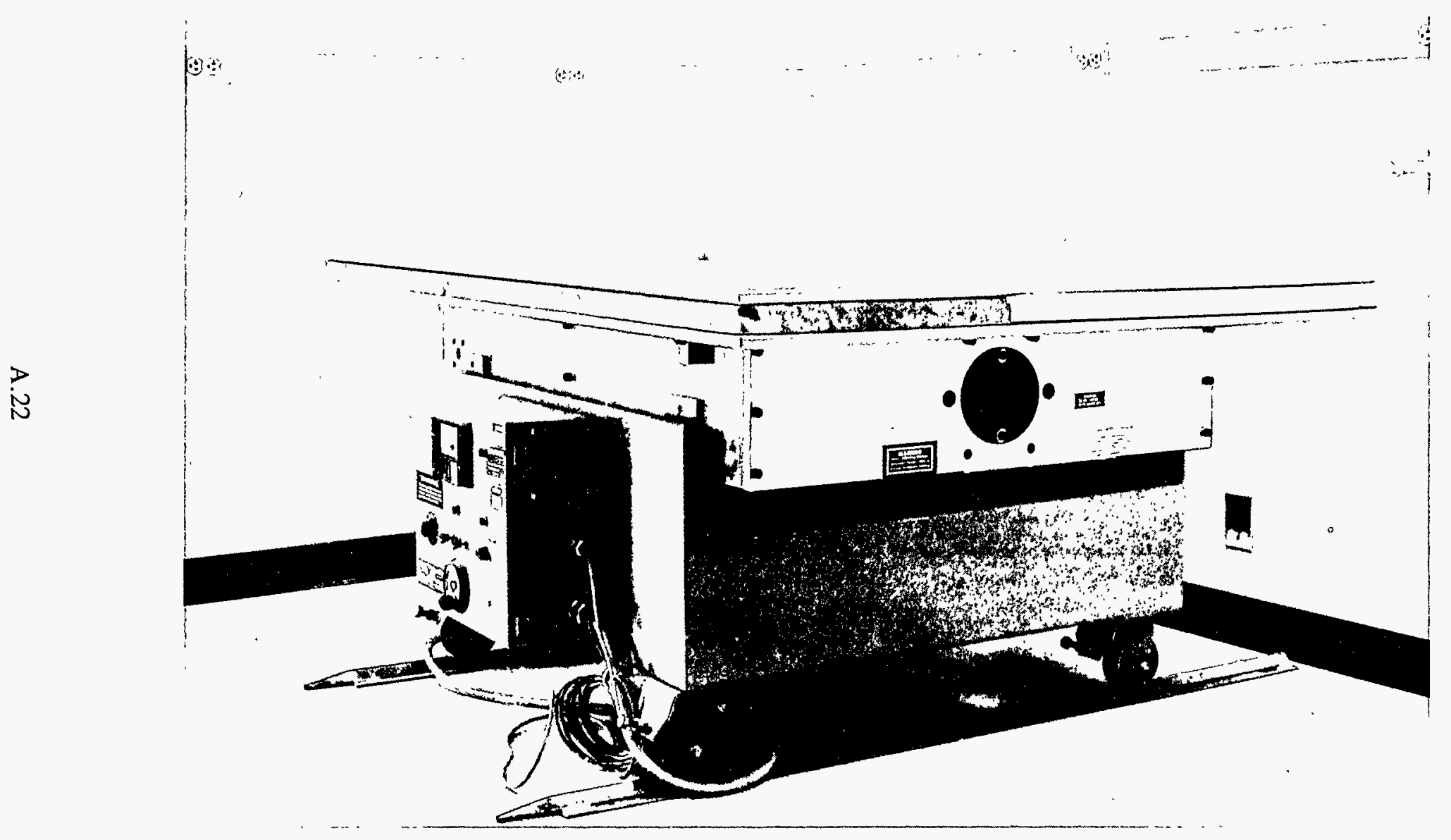

Figure A.21. Mechanical Vibration Table (frequency range: 8 to $60 \mathrm{~Hz}$, maximum acceleration: $3.2 \mathrm{~g}$, maximum test load: $680 \mathrm{~kg}$ ) 


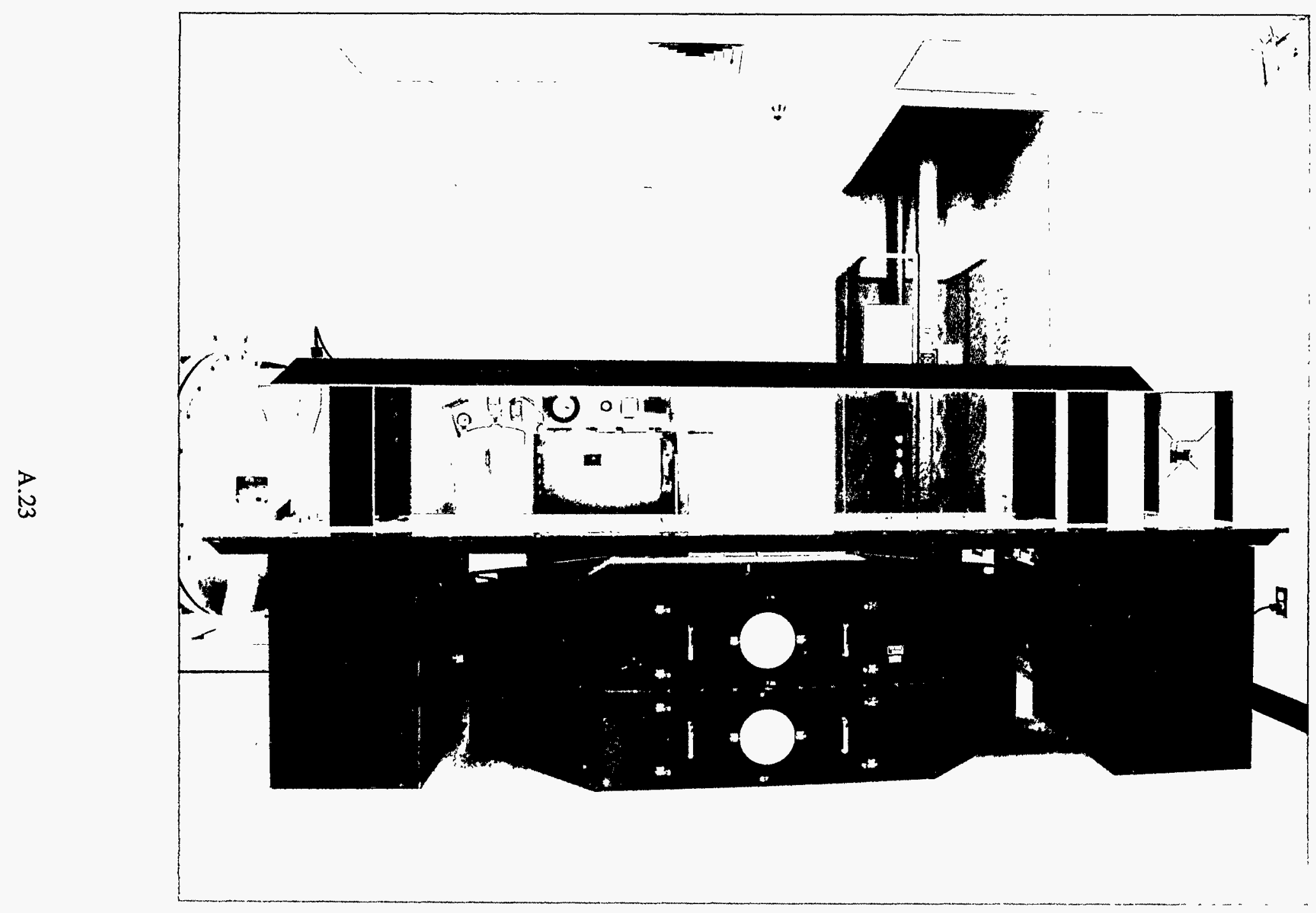

Figure A.22. Military Standard 462 Radio Frequency Exposure System, (top) Range 0.3 to $35 \mathrm{mHz}$, Maximum Field Strength $100 \mathrm{v} / \mathrm{m}$. Transverse electromagnetic cell (bottom), range DC-200 $\mathrm{mHz}$, maximum field strength $650 \mathrm{v} / \mathrm{m}$. 


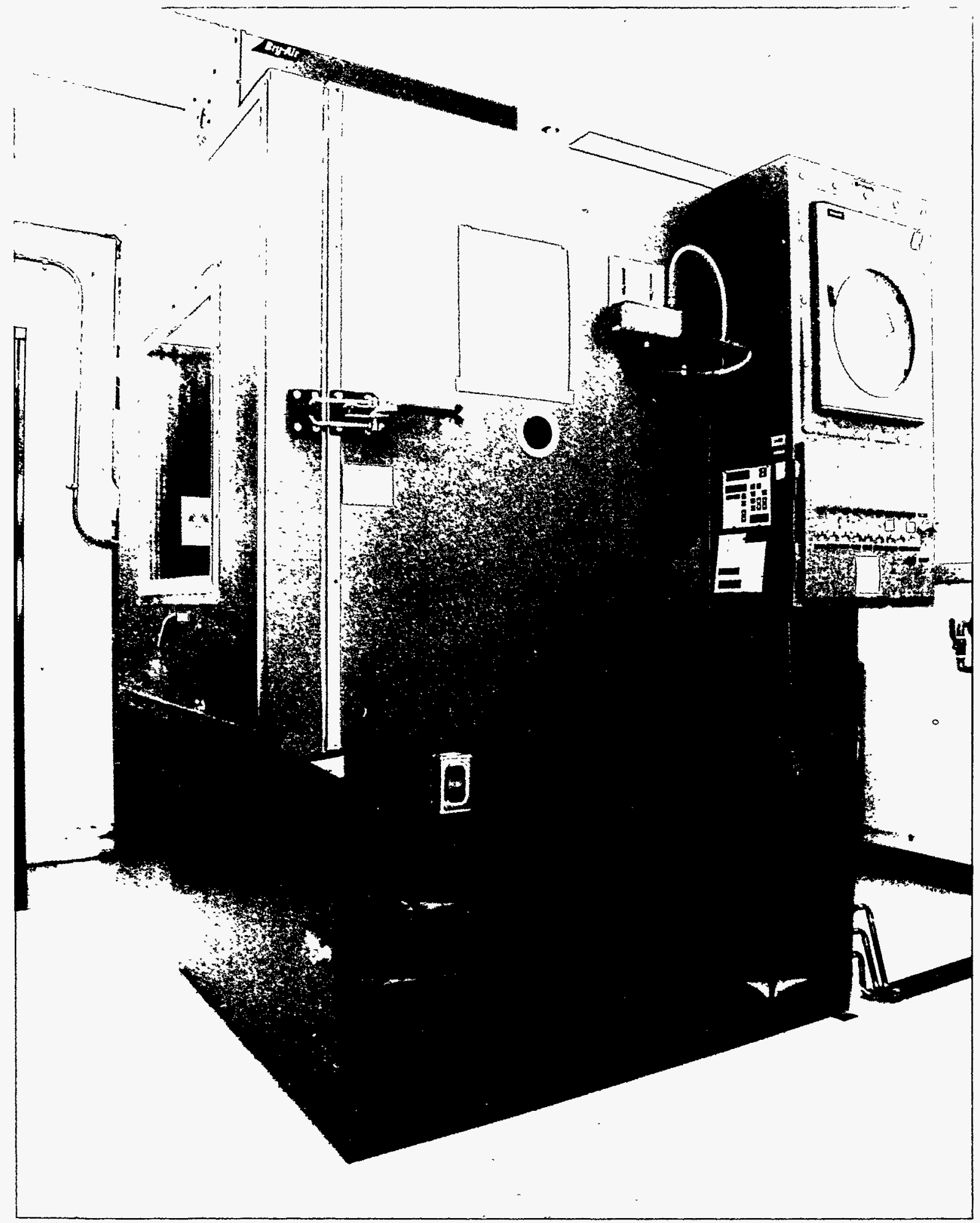

Figure A.23. Environmental Chamber (range $-68^{\circ} \mathrm{C}$ to $177^{\circ} \mathrm{C}, 5 \%$ to $95 \% \mathrm{RH}$ ) 


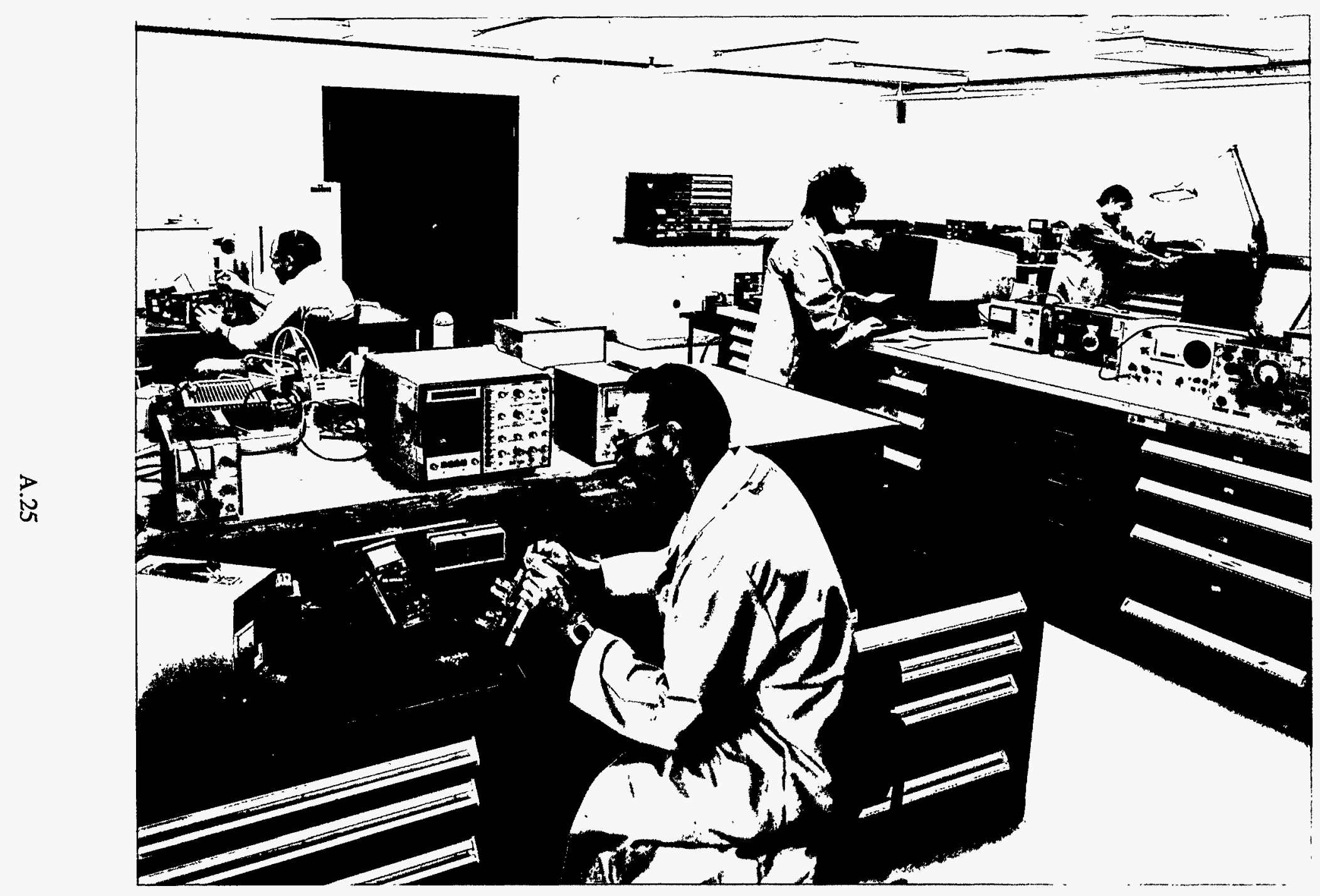

Figure A.24. Instrument Repair Shop. The instrument shop forms part of a trailer complex that is permanently attached to the south wing of the laboratory. This shop maintains and repairs all portable and semiportable radiological instruments routinely used on the Hanford Site. 


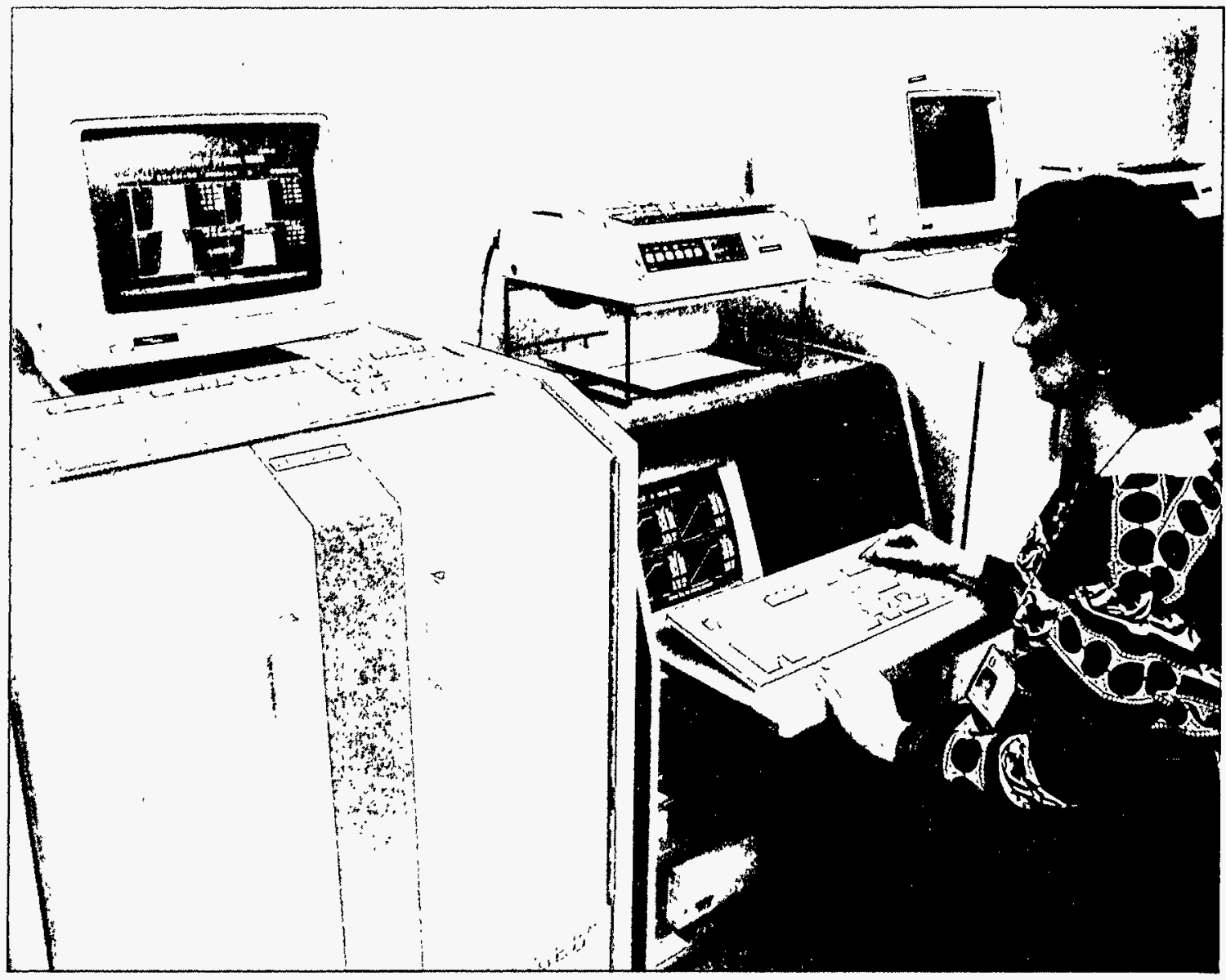

Figure A.25. The Harshaw 8800 Reader. This system, controlled by a personal computer, processes up to 2,000 dosimeters per day. The dosimeters are "read" by heating each of the four TLD chips on the TLD card according to a programmed time-temperature profile. The light emitted from the chips is proportional to the radiation dose received and is measured with low noise photomultiplier tubes. The electronic data include 800 data points of temperature information and 800 data points of glow information for each dosimeter. Real-time process quality control is implemented through user adjustable limits on reference light readings, photomultiplier tube noise readings, and control dosimeter readings. Any reading exceeding a limit will stop the reader. 


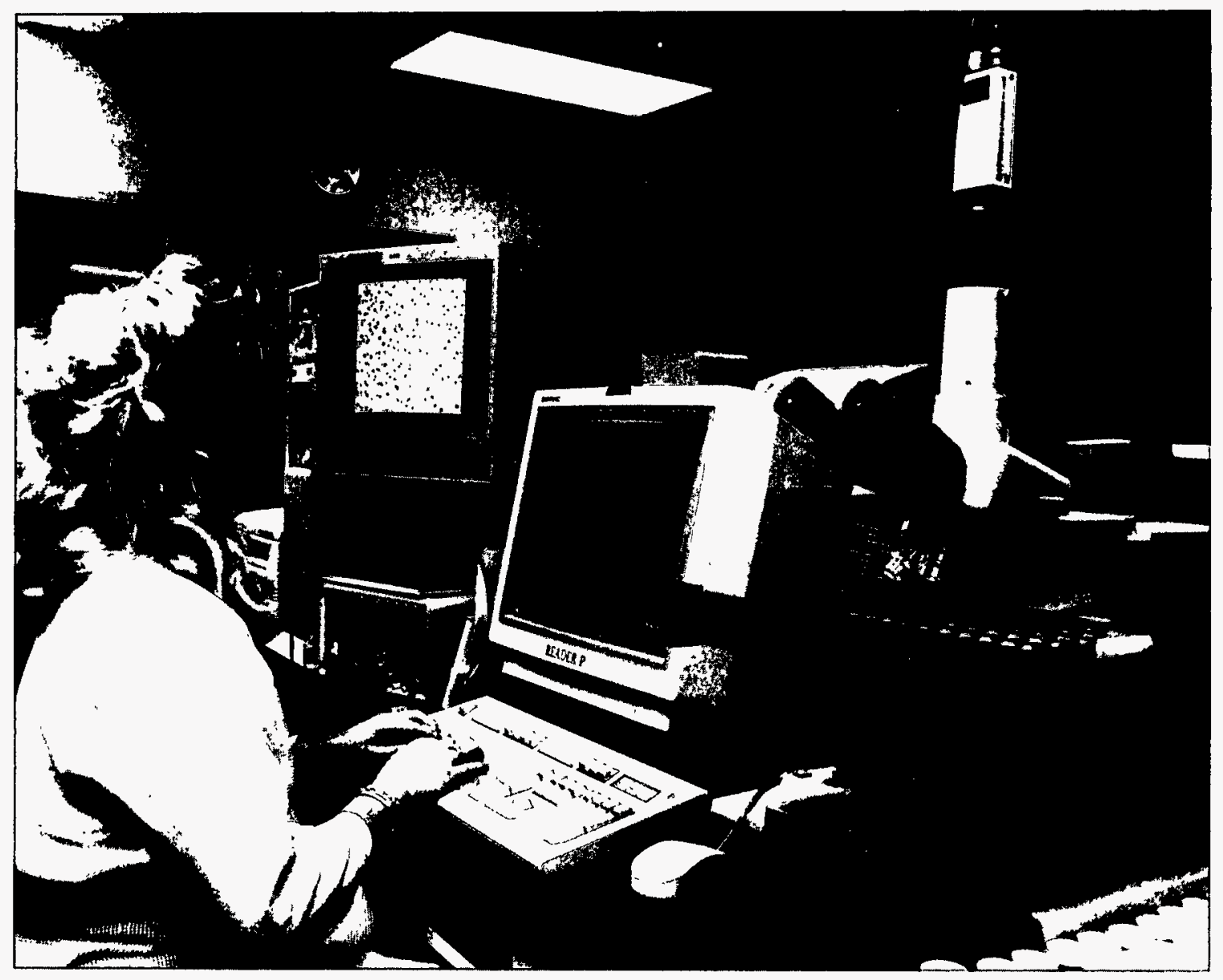

Figure A.26. Track Etch Dosimeter (TED) Reader. TED foils are included as one component of the Hanford combination neutron dosimeter. The foils are small sheets of CR-39 polycarbonate plastic. When neutrons strike the plastic, they leave microscopic tracks. These tracks are enlarged by electro-chemical etching so that they can be counted using a microscope with a camera attached. Image recognition software designed at Battelle "recognizes" and counts the tracks in each field of view before the automated stage moves the foil to a new position for another count. The number of tracks counted is directly proportional to the neutron dose received. 


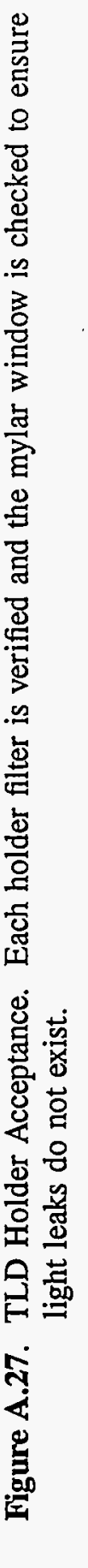




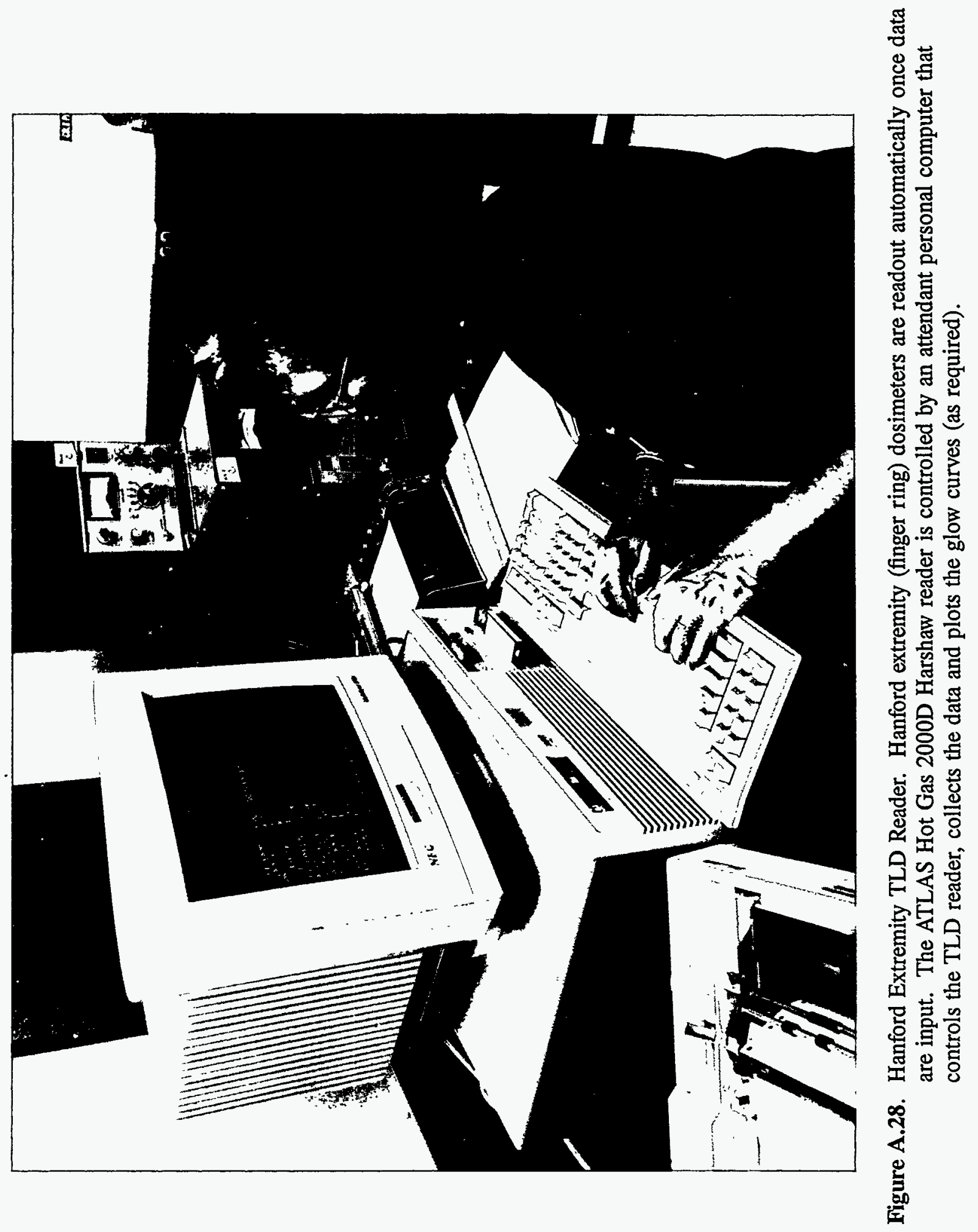




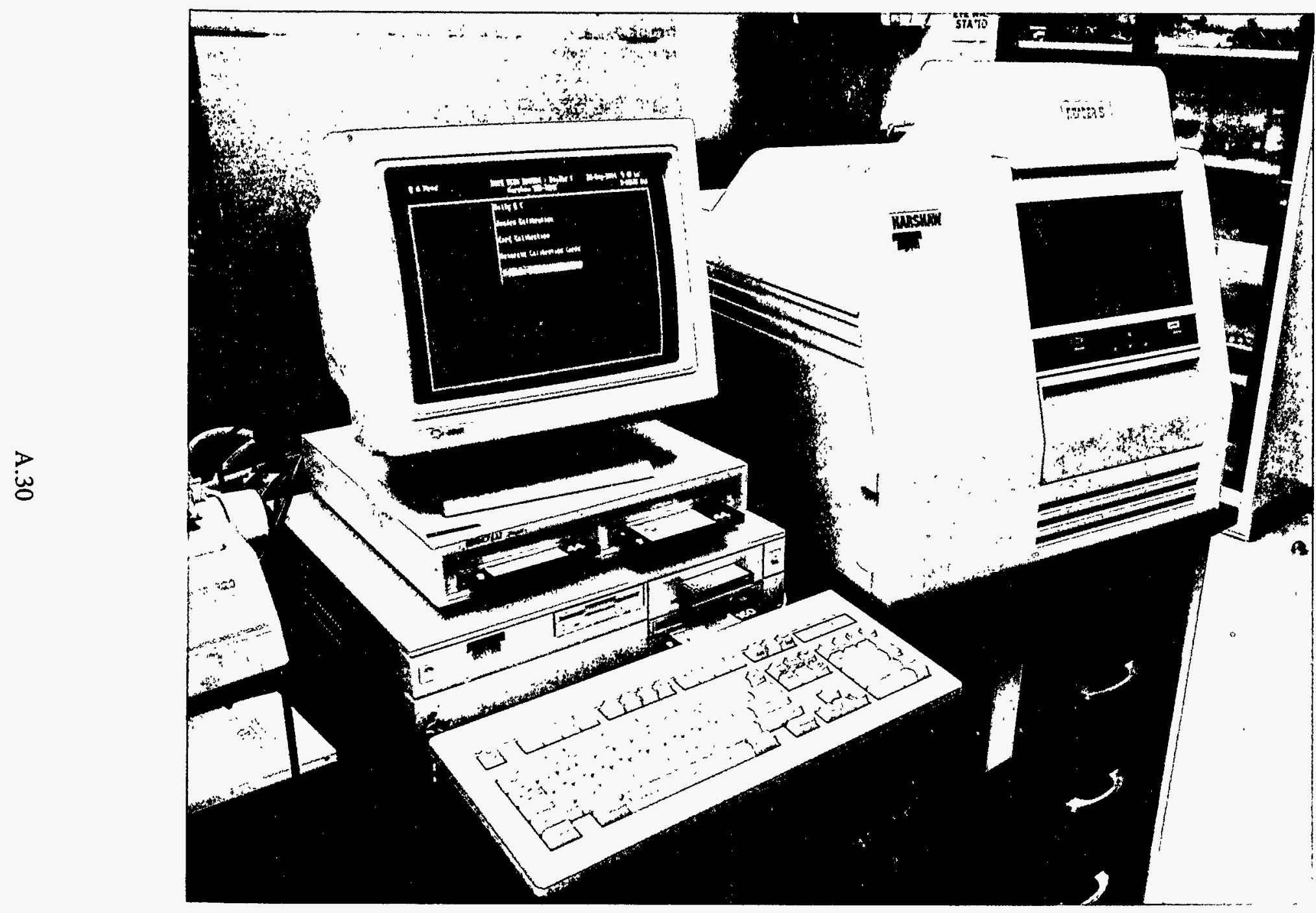

Figure A.29. Harshaw TLD 6600 Extremity Reader. The next generation extremity TLD reader is the Harshaw TLD 6600 reader, which will be implemented January 1,1996 for extremity dosimeters. 


\section{Distribution}

No. of

Copies

Offsite

12 DOE/Office of Scientific and

Technical Information

P.O. Box 62

Oak Ridge, TN 37831

Ron Burdett

TMA Hanford

P.O. Box 1318, MS N1-06

Richland, WA 99352

Ron Daily

EG\&G Mound

P.O. Box 3000, Bldg. 91

Miamisburg, $\mathrm{OH} 45342$

Albert I. Davis

TMA Hanford

P.O. Box 1318, MS X0-21

Richland, WA 99352

Dan Dotson, MS 12A1

CEBAF

12000 Jefferson Ave.

Newport News, VA 23606

Steve Hoadley

EG\&G Mound

P.O. Box 3000

Miamisburg, OH 45342

George Hughes

Brookhaven National Lab

Bldg. 348

Upton,. NY 11973

Bob Kennard

EG\&G Rocky Flats

P.O. Box 464, Bldg. 790

Golden, CO 80402-0464
No. of

Copies

Michael Sawada

Lawrence Berkeley Lab

1 Cyclotron Road, MS 7-222

Berkeley, CA 94720

Chuck Searcy, Area 6, CP-50

REECO/Nevada Test Site

P.O. Box 98521, MS 233

Mercury, NV 89023

David Sinton

Sandia National Lab

Dept. 7713, MS 1095

Albuquerque, NM 87185

Paul Zahra

Brookhaven National Lab

Bldg. 129

Upton, NY 11973

4 DOE Albuquerque Field Office

J. B. Martin

Battelle Pantex

Pantex Plant

P.O. Box 30020

Amarillo, TX 79120

L. M. Coco

Mound Laboratory

EG\&G

Mound Applied Technologies

P.O. Box 3000

Miamisburg, OH 45342

J. M. Graf

Los Alamos National Laboratory

P.O. Box 1663

Los Alamos, NM 87545

Distr. 1 
No. of

Copies

R. M. Rogers

EG\&G Rocky Flats

Rocky Flats Plant

P.O. Box 464

Golden, CO 80402-0464

\section{DOE Chicago Field Office}

\author{
A. E. Keuhner \\ Brookhaven National Laboratory \\ Upton, NY 11973
}

R. E. Toohey

Argonne National Laboratory

9700 South Cass Avenue

Argonne, IL 60439

DOE Idaho Field Office

H. D. Christiansen

Westinghouse Idaho Nuclear

Company, Inc.

P.O. Box 4000

Idaho Falls, ID 83404

DOE Nevada Field Office

B. P. Smith

Reynolds Electrical and

Engineering Co., Inc.

P.O. Box 98521

Las Vegas, NV 89193

\section{DOE Oak Ridge Field Office}

J. S. Bogard

Oak Ridge National Laboratory

Martin Marietta Energy

Systems, Inc.

P.O. Box 2008

Oak Ridge, TN 37831
No. of

Copies

J. B. Hunt

Y-12 Plant

Martin Marietta Energy

Systems, Inc.

P.O. Box 2008

Oak Ridge, TN 37831

DOE San Francisco Field Office

C. T. Prevo

Lawrence Livermore National

Laboratory

P.O. Box 808

Livermore, CA 94550

DOE Savannah River Field Office

D. A. Stevenson

Westinghouse Savannah River Company

Savannah River Plant

P.O. Box 616

Aiken, SC 29802

Onsite

4 DOE Richland Operations Office

D. L. Clark, A5-55

D. T. Evans, A5-55

J. B. Hall, A5-55

D. L. Rice, A5-55

2 Bechtel Hanford, Inc.

J. D. Moroney, III (TMA), H4-88

J. E. Tarpinian, H4-87

3 Hanford Environmental Health Foundation

H. S. Gilchrist, H1-77

R. H. Ronish, H1-02

M. J. Swint, H1-02 
No. of

Copies

3 Westinghouse Hanford Company

W. A. Decker, Jr., S0-06

R. E. Heineman, S6-65

T. J. Kelly, S0-06

Washington State University (Tri-Cities)

R. L. Kathren, H2-52

54 Pacific Northwest Laboratory

D. E. Bihl, A3-60

L.M.G. Ballou, P7-18

G. L. Carter, P7-01

J. E. Edmond, P7-01

D. M. Fleming, P7-01

J. J. Fix, P7-02

T. J. Froelich, P7-01

R. W. Goles, P7-01 (20)

D. P. Higby, P7-78
No. of

Copies

G. R. Hoenes, P7-79

J. R. Houston, A3-60

J. R. Johnson, K3-57

M. L. Johnson, P7-01

D. E. Linklater, P7-01

M. Lyon, A3-60

T. P. Lynch, B1-60

J. C. McDonald, P7-03

L. H. Munson, K3-55

I. C. Nelson, K3-54

P. C. Olsen, B1-60

J. D. Peters, P7-02

R. K. Piper, P7-03

B. A. Rathbone, P7-02

D. R. Sisk, K3-55

K. L. Soldat, K3-53

K. L. Swinth, K3-53

R. A. Walters, K1-50

Publishing Coordination

Technical Report Files (5)

Radiation Protection Historical Files (c/o V. L. Berndt, A3-60) (2) 